\title{
Intracortical Microstimulation Modulates Cortical Induced Responses
}

\author{
Mathias Benjamin Voigt, ${ }^{1,2} \odot$ Prasandhya Astagiri Yusuf, ${ }^{1,2,3}$ and ${ }^{-A n d r e j ~ K r a l ~}{ }^{1,2}$ \\ ${ }^{1}$ Institute of AudioNeuroTechnology and Department of Experimental Otology, Hannover Medical School, 30625 Hannover, Germany, ${ }^{2}$ Cluster of \\ Excellence "Hearing4all", 30625 Hannover, Germany, and ${ }^{3}$ Department of Medical Physics/Medical Technology Cluster IMERI, Faculty of Medicine \\ Universitas Indonesia, 10430 Jakarta, Indonesia
}

Recent advances in cortical prosthetics relied on intracortical microstimulation (ICMS) to activate the cortical neural network and convey information to the brain. Here we show that activity elicited by low-current ICMS modulates induced cortical responses to a sensory stimulus in the primary auditory cortex (A1). A1 processes sensory stimuli in a stereotyped manner, encompassing two types of activity: evoked activity (phase-locked to the stimulus) and induced activity (non-phase-locked to the stimulus). Time-frequency analyses of extracellular potentials recorded from all layers and the surface of the auditory cortex of anesthetized guinea pigs of both sexes showed that ICMS during the processing of a transient acoustic stimulus differentially affected the evoked and induced response. Specifically, ICMS enhanced the long-latency-induced component, mimicking physiological gain increasing top-down feedback processes. Furthermore, the phase of the local field potential at the time of stimulation was predictive of the response amplitude for acoustic stimulation, ICMS, as well as combined acoustic and electric stimulation. Together, this was interpreted as a sign that the response to electrical stimulation was integrated into the ongoing cortical processes in contrast to substituting them. Consequently, ICMS modulated the cortical response to a sensory stimulus. We propose such targeted modulation of cortical activity (as opposed to a stimulation that substitutes the ongoing processes) as an alternative approach for cortical prostheses.

Key words: auditory cortex; cortical implant; hearing; neuroprosthetic; oscillation

\section{Significance Statement}

Intracortical microstimulation (ICMS) is commonly used to activate a specific subset of cortical neurons, without taking into account the ongoing activity at the time of stimulation. Here, we found that a low-current ICMS pulse modulated the way the auditory cortex processed a peripheral stimulus, by supra-additively combining the response to the ICMS with the cortical processing of the peripheral stimulus. This artificial modulation mimicked natural modulations of response magnitude such as attention or expectation. In contrast to what was implied in earlier studies, this shows that the response to electrical stimulation is not substituting ongoing cortical activity but is integrated into the natural processes.

\section{Introduction}

Intracortical microstimulation (ICMS) is widely used in neuroscience to identify a causal connection between cortical neuronal activity and a specific brain function (Cicmil and Krug, 2015). Its main use is the activation of a subset of the cortical network by

\footnotetext{
Received April 11, 2018; revised June 19, 2018; accepted July 6, 2018.

Author contributions: M.B.V. wrote the first draft of the paper; M.B.V., P.A.Y., and A.K. edited the paper. M.B.V. and A.K. designed research; M.B.V. performed research; M.B.V. and P.A.Y. analyzed data.

This work was supported by the German Research Foundation, Cluster of Excellence "Hearing4all” (EXC 1077). We thank Karl-Jürgen Kühne and Daniela Kühne for support during the experiments and Dr. Peter Hubka for extensive discussion of the data presented herein.

The authors declare no competing financial interests.

Correspondence should be addressed to Mathias B. Voigt, Institute of AudioNeuroTechnology, OE 8891, Hannover Medical School, Stadtfelddamm 34, 30625 Hannover, Germany. E-mail: voigt.mathias@mh-hannover.de. DOI:10.1523/JNEUROSCI.0928-18.2018

Copyright $\odot 2018$ the authors $\quad 0270-6474 / 18 / 387774-13 \$ 15.00 / 0$
}

evoking action potentials in neurons close to the stimulation electrode (Tehovnik, 1996; Clark et al., 2011; Histed et al., 2013). In addition to basic neuroscientific research, this method has been used for the development of invasive neural prostheses (Schwartz, 2004; Lebedev, 2016; Lebedev and Nicolelis, 2017). Most progress in the development of implantable cortical prostheses for humans has been achieved in the somatosensory and motor systems of tetraplegic patients (Aflalo et al., 2015; Flesher et al., 2016; Pandarinath et al., 2017).

In neural prostheses ICMS is used to evoke a specific function of the brain (e.g., elicit a percept or affect a muscle) by activating a neuronal population that is providing this particular function. In theory, activating the responsible network "naturally", i.e., comparable with physiological activation, would provide optimal control of the targeted cortical processing. One precondition to 
A

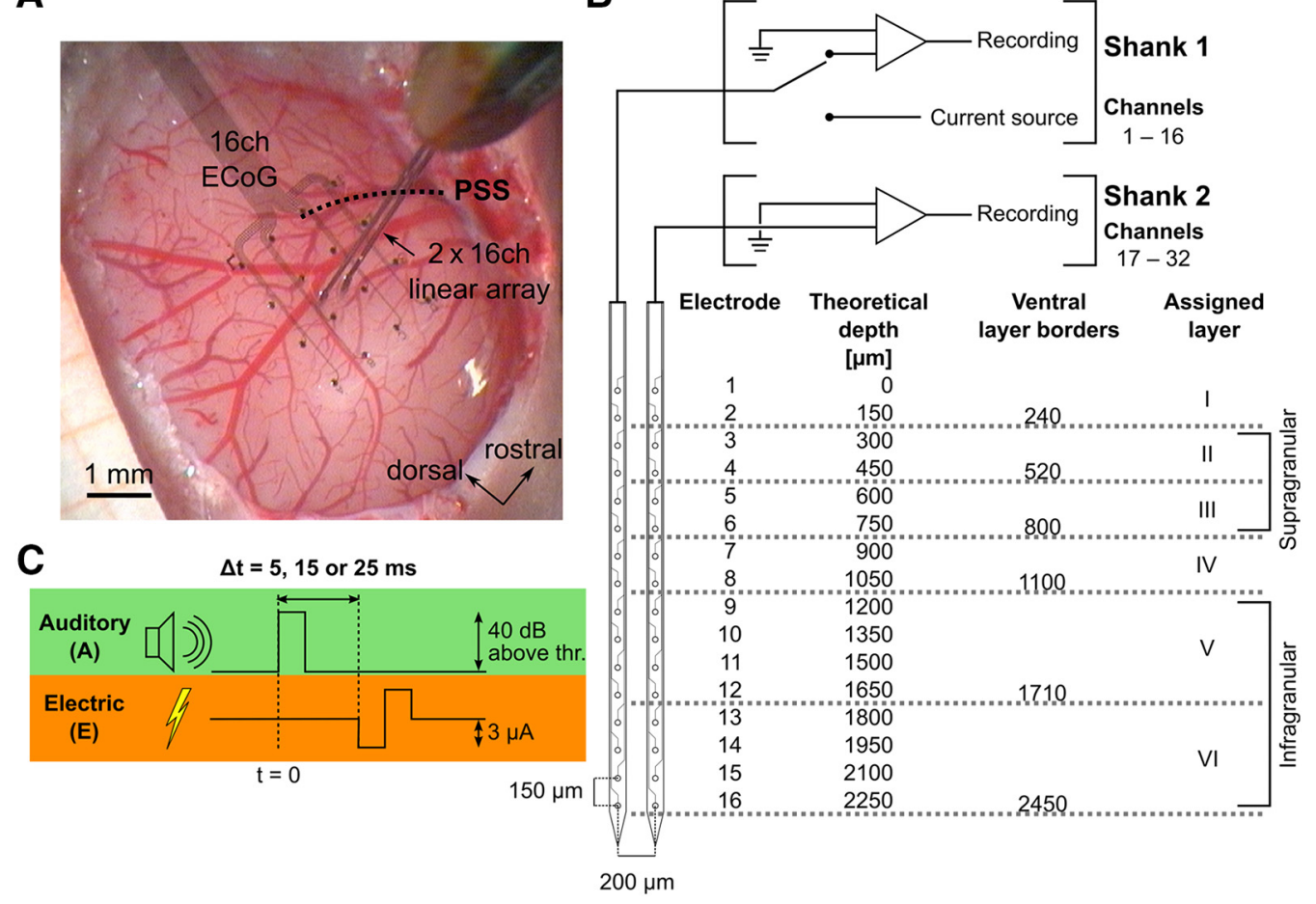

Figure 1. Methodology. A, Photograph showing the exposed cortex and the recording electrode arrangement. The double shank recording/stimulation electrode array was inserted through a hole in the substrate of the rectangular 16-channel surface electrode array placed on A1. PSS, Pseudo-sylvian sulcus. $\boldsymbol{B}$, Recording/stimulation channel parameters. The first 16 channels (Shank 1 ) of the depth electrode array could be connected to a dedicated current source. Cortical layers have been assigned to single electrodes according to literature (Wallace and Palmer, 2008) and current source density profiles (Voigt et al., 2017). C, Schematic of the stimulus combination used. Auditory (condensation click, $50 \mu$ s, $40 \mathrm{~dB}$ above ABR hearing threshold) and electric stimuli (biphasic, 200 $\mu \mathrm{s} /$ phase, cathodic-leading, $\sim 3 \mu \mathrm{A}$ ) have been presented either alone or in combination. In combined conditions the auditory stimulus was always leading the electric stimulus with a delay ( $\Delta t$ ) of 5,15 , or 25 ms of the electric stimulus.

allow physiological-like activation is that the response to ICMS is integrated into ongoing cortical processing. Although the influence of the network state (Buonomano and Maass, 2009) on cortical processing has been a well-known fact (Arieli et al., 1996; Henry and Obleser, 2012), internal cortical processing at the moment of stimulus presentation received insufficient attention. Only recently, discussions on adapting neuroprosthetical stimulation to ongoing cortical processes have been initiated (Panzeri et al., 2016). As examples of the effectiveness of such an approach, the effect size of transcranial magnetic stimulation increased when stimulation was confined to a specific EEG phase (Zrenner et al., 2018) and using the internal cortical state as an additional prediction variable increased information yield from recorded neuronal activity (De Feo et al., 2017), an important bottle-neck in brain-computer interfaces (Baranauskas, 2014; Tehovnik and Chen, 2015; Panzeri et al., 2016).

Here we show that ICMS can lead to a neuronal response that becomes integrated into ongoing processes similar to an acoustic stimulus, in contrast to substituting the physiological activity with artificially generated activity. We recorded activity from the surface and the depth of the primary auditory cortex (A1; Fig. 1A) of guinea pigs during acoustic stimulation, ICMS, and a combination of both (Fig. $1 B, C$ ). Oscillatory activity documented the expected response of A1 to transient acoustic stimuli, consisting of two types of activity: an early phase-locked ("evoked") response and a late non-phase-locked ("induced") response. This has been previously described in the auditory cortex of rodents (Delano et al., 2008), cats (Yusuf et al., 2017), nonhuman primates (Brosch et al., 2002; Steinschneider et al., 2008), and humans (Trautner et al., 2006; Dimitrijevic et al., 2017).
The two response components, the evoked and induced response, are usually interpreted as corresponding to two stages of processing. The evoked component reflects the thalamocortically conveyed bottom-up processes, whereas the induced responses result from interaction of such thalamo-cortical inputs with weaker corticocortical inputs (Poort et al., 2012; Klink et al., 2017). Functionally, the induced response component likely represents top-down feedback processes linking external stimuli to an internal cortical model of the environment, i.e., combining externally driven sensory input with internally generated predictions (Engel et al., 2001; Chen et al., 2012; Morillon et al., 2015).

Low-current ICMS alone, at a current level sufficient to generate significant local neuronal activity (Voigt et al., 2017), showed an evoked component, but no induced component. Adding ICMS to an acoustic stimulation differentially affected oscillatory responses: the induced responses were supra-additively amplified, whereas the evoked responses were reduced. A phasebased response variability analysis revealed an influence of the prestimulus network state on the response amplitude similarly in ICMS and acoustic stimulation. Consequently, low-current intracortical microstimulation can be physiologically integrated into the cortical processing and modulate cortical responses.

\section{Materials and Methods}

Animals and preparation. Data from nine Dunkin Hartley guinea pigs (Crl:HA; Charles River Laboratories; 7 male, 2 female) weighing 350$440 \mathrm{~g}$ were used. Data of one additional animal (male, $500 \mathrm{~g}$ ) were excluded from analysis, because recordings included a secondary auditory field (based on the morphology of averaged local field potentials (LFPs) and response latencies). High current electrical stimulation data were 
taken from a previous study comparing effects of low- and high- current stimulation (Voigt et al., 2017).

All experiments were conducted in accordance with EU Directive 2010/63/EU, the German law for the protection of animals, and were approved by the ethics committee of the government of the state of Lower Saxony, Germany.

The general methodology followed standard procedures of our laboratory for in vivo recordings and intracortical microstimulation in the auditory cortex of guinea pigs, which have been previously described in detail (Voigt et al., 2017).

In brief, anesthesia was induced by injection of a mixture of ketamine hydrochloride (50 mg/kg, 10\% Ketamin, WDT) and xylazine hydrochloride $(10 \mathrm{mg} / \mathrm{kg}, 2 \%$ Xylazin [medistar]), supplemented with atropine sulfate $(0.1 \mathrm{mg} / \mathrm{kg}$, B. Braun Melsungen AG) and maintained by injection of a mixture with reduced xylazine $(10 \mathrm{mg} / \mathrm{kg}$ ketamine, $5 \mathrm{mg} / \mathrm{kg}$ xylazine). Carprofen ( $0.05 \mathrm{ml} /$ animal; Rimadyl, Pfizer $\mathrm{GmbH})$ was administered per animal to provide general analgesia. Core body temperature was controlled using a closed-loop heating blanket. Following tracheotomy the animals were artificially ventilated. Anesthetic depth and physiological status were continuously controlled by monitoring the body temperature, ECG, expiratory $\mathrm{CO}_{2}$ concentration and respiratory pressure. To determine individual hearing thresholds auditory brainstem responses $(\mathrm{ABR})$ were recorded.

Cortical recordings. The animals were fixed in a stereotaxic frame inside a sound-attenuating, electrically shielded recording chamber, using a metal bolt cemented to the frontal bones using dental cement (Paladur, Heraeus). The right auditory cortex was exposed by a broad craniotomy and the dura was resected. The individual position of the auditory cortex was mapped by recording cortical surface responses to acoustic clicks [50 $\mu$ s clicks, $40 \mathrm{~dB}$ above auditory brainstem response (ABR) hearing threshold] using either several placements of a 16-channel surface grid ( $n=7$; Blackrock Microsystems; Konerding et al., 2018), or a single-channel $\mathrm{Ag} / \mathrm{AgCl}$ ball electrode $(n=2$, diameter $\sim 0.5 \mathrm{~mm})$. Layer-specific depth recordings were performed using a double-shank, 16-channel per shank, multielectrode array (A2x16-10 mm-150-500177, NeuroNexus; Fig. $1 A, B)$. In 7 of 9 experiments the depth electrodes were inserted centrally through a hole in the substrate of the surface grid electrode. The shanks were oriented perpendicular to the cortical surface to span the whole cortical depth. Single electrodes were assigned to a cortical layer based on penetration depth, ventral layer border values available in the literature (Wallace and Palmer, 2008; Fig. 1B) and current source density profiles, an approach validated by histological reconstruction (Voigt et al., 2017). Broad frequency cortical potentials were recorded, hardware filtered ( $1 \mathrm{~Hz}$ to $9 \mathrm{kHz}$ ), and digitized at a sampling rate of $22 \mathrm{kHz}$ using an Alpha Omega electrophysiology system (AlphaLab SnR, AlphaOmega).

Acoustic and intracortical electric stimulation. Acoustic stimulation (50 $\mu$ s condensation clicks, $40 \mathrm{~dB}$ above ABR hearing threshold) was presented to the contralateral ear using a calibrated loudspeaker (DT-48, Beyerdynamic) connected with the outer ear canal using a plastic cone. Intracortical microstimulation was performed on all of the 16 electrodes on the first shank of the multielectrode array using built-in current sources of the Alpha Omega system (Fig. 1B). A subcutaneous $\mathrm{Ag} / \mathrm{AgCl}$ electrode in the neck served as current return. Stimulation consisted of biphasic, cathodic-leading, charge-balanced, square-wave current pulses (200 $\mu$ s per phase, no interphase delay). Stimulation intensity was $3.11 \pm$ $0.74 \mu \mathrm{A}$ (mean $\pm \mathrm{SD}, n=9$, range: $1.7-4.2 \mu \mathrm{A}$ ), as determined by measuring the voltage over a $100 \Omega$ resistor placed in series in the current return path (Voigt et al., 2017), except for the high current example data taken from a previous study, in which stimulation intensity was $\sim 45 \mu \mathrm{A}$.

Additionally to acoustic and electric stimulation in solitary conditions, combined acoustic and electric stimulation was presented. In these conditions the electric stimulation always followed the acoustic click, with delays of 5,15 , or $25 \mathrm{~ms}$ (Fig. 1C). The sequence of stimulation modalities in each experiment was as follows: acoustic only then electric only, followed by combined stimulation, with the sequence of different stimulus delays presented in pseudorandom order from experiment to experiment.
Each stimulus/stimulus combination was repeated 32 times with a repetition rate of $\sim 1 \mathrm{~Hz}$. The first and last trials of the 32 stimulus repetitions were discarded to remove edge artifacts resulting from the connection of electrodes to the current sources. Further analyses therefore included 30 trials. For all analyzes and all images $t=0$ designates the time point of acoustic stimulation onset for acoustic only and combined stimulation, and the time point of electric stimulation onset in electric only conditions.

Data processing and time-frequency analysis. The digitized data were analyzed off-line using custom-made MATLAB (MathWorks) procedures. All custom scripts used to analyze the data and generate the figures in this publication can be found online (https://github.com/ mbvoigt/ModulatingICMS).

Electrical stimulation artifacts were removed by linearly interpolating the data between 0 and $3 \mathrm{~ms}$ after stimulation onset. The data were split by filtering into LFPs and multiunit activity (MUA), using a zero-phase shift, second-order Butterworth filter with a cutoff frequency of $150 \mathrm{~Hz}$ (LFP, low-pass) and $300 \mathrm{~Hz}$ (MUA, high-pass), respectively. Single spiking events were detected by a custom threshold crossing algorithm following the threshold criterion of Quiroga et al. (2004). Blinding in regard to the stimulus modality presented was not possible during data analysis.

Time-frequency analyses were performed on the unfiltered raw data, which was down-sampled to $1 \mathrm{kHz}$ and demeaned by subtracting the mean of the baseline period ( -0.5 to $-0.15 \mathrm{~s}$ relative to stimulation). Decomposition of 1-s-long epochs ( -0.5 to $0.5 \mathrm{~s}$ relative to stimulation) into time-frequency space was done by Morlet wavelet (width $=6$ cycles) convolution, with wavelets from 7 to $95 \mathrm{~Hz}$ in $2 \mathrm{~Hz}$ steps, using the "fieldtrip toolbox" for MATLAB (Oostenveld et al., 2011). For total power analysis the median over the 30 stimulus repetitions was normalized to the baseline period ( -0.5 to $-0.15 \mathrm{~s}$ rel. to stimulation) by calculating the change in decibel values. For combined stimulus conditions, electrodes with a baseline corrected mean value of $>6 \mathrm{~dB}$ between 45 and $55 \mathrm{~Hz}$ in the poststimulus period were considered to be contaminated by artifacts from the high-voltage current sources and removed from further analyses. Spatial plots of surface electrodes were smoothed by firstorder linear interpolation.

Statistical analysis. All statistical analyses, for example multifactorial ANOVAs or one-sample $t$ tests were performed using the statisticstoolbox of MATLAB. All statistical tests were performed two-sided. False discovery rate compensation, i.e., correction for multiple comparisons, was done using the Benjamini-Hochberg step-up procedure on the results of one-sample $t$ tests (Benjamini and Hochberg, 1995). Clusterbased permutation testing was done with 1000 randomizations, using the "fieldtrip toolbox". When not noted otherwise values are given as mean \pm SEM. Following Cohen (2014) the critical value for statistical significance of the intertrial coherence was calculated for $n=30$ stimulus repetitions and $\alpha=0.01$, as follows:

$$
\mathrm{P}_{\text {crit }}=\sqrt{\frac{-\ln (0.01)}{30}}=0.3918 .
$$

A model for the surface potential amplitude in response to ICMS in different depths was designed as the sum of a linear decrease with increasing stimulation depth and a normalized Gaussian function with an optimum in middle cortical layers:

$$
y(x)=-a x+\frac{1}{\sqrt{2 \pi \sigma^{2}}} \exp \left[-\frac{(x-\mu)^{2}}{2 \sigma^{2}}\right],
$$

where $x$ denotes the stimulation depth, $y(x)$ the resulting surface potential amplitude, $a$ the slope of the linear component, and $\mu$ and $\sigma$ the parameters of a normalized Gaussian function. The phase of the LFP for the trial-to-trial analysis was calculated using the Hilbert transform of the $150 \mathrm{~Hz}$ low-pass filtered data. Prestimulus phase influence was calculated for each electrode separately, with data pooled over all 9 experiments and all 30 trials. For the quantification of the influence of the prestimulus phase, the $z$-scored single-trial peak amplitudes were averaged with respect to the phase at different prestimulus times $(\Delta \varphi)$, in eight bins in the range of $-\pi$ to $\pi$. The modulation index was calculated by subtracting the minimal bin average from the maximal bin average. 

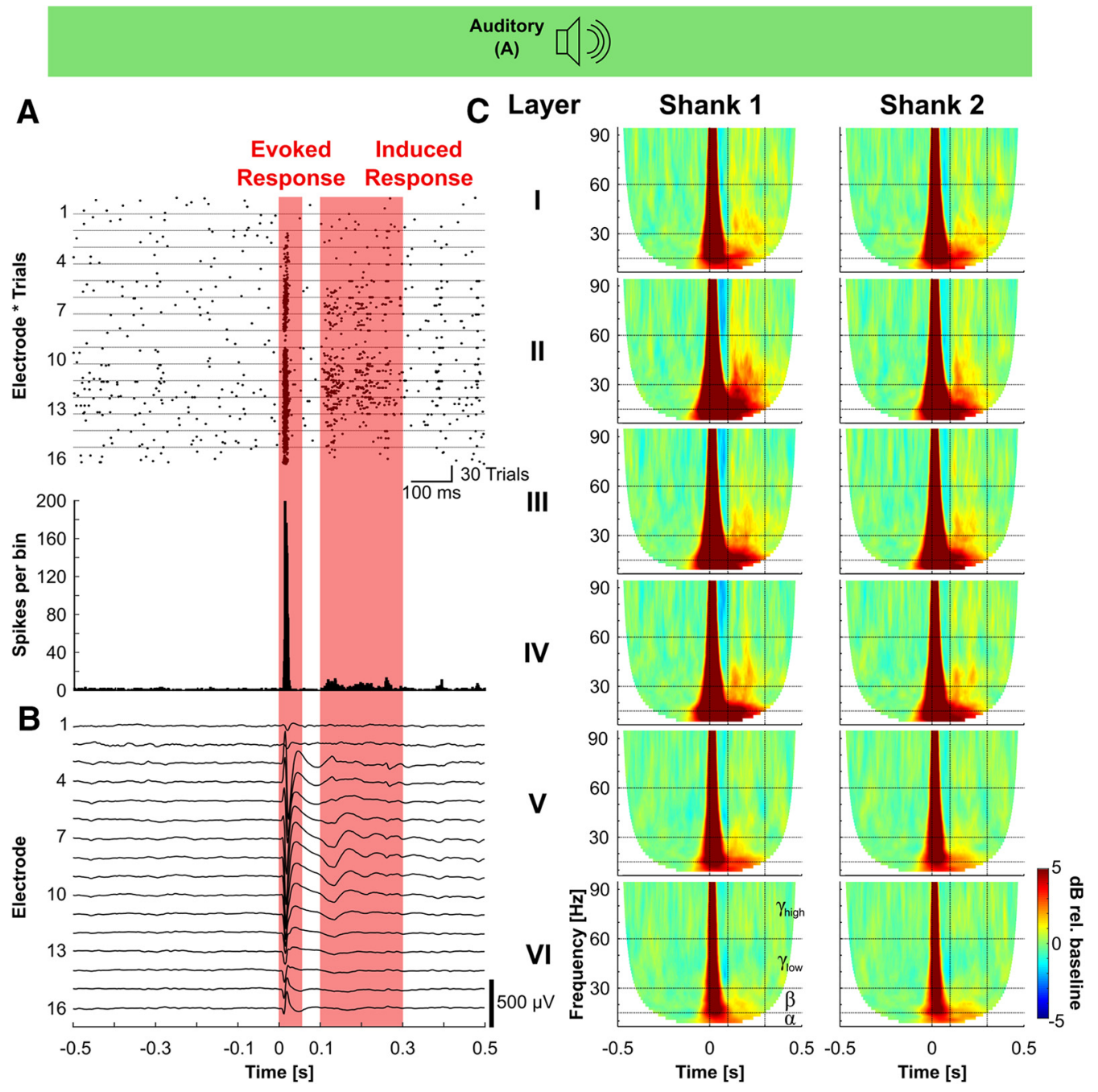

Figure 2. Response of A1 to transient acoustic stimulation. A, Example of multiunit activity elicited by acoustic click stimuli. In the raster plot of the first 16 channels (top), as well as the collapsed peristimulus time histogram (bottom) a strong primary excitation (evoked response) is visible, followed by a weaker secondary excitation (induced response). In the raster plot (top), each dot marks one action potential. The horizontal lines separate the data from different electrodes. For each electrode the response to each of 30 stimulus repetitions is shown stacked. $\boldsymbol{B}$, Whereas the evoked response is visible in the trial-averaged LFP response, the induced response is more difficult to distinguish from background activity. C, Grand mean time-frequency representation (baselinecorrected, total power) showed the strong early response component, as well as a longer-latency response in the 100-300 ms time window (vertical dashed lines). Horizontal dashed lines show borders of the frequency band definition used herein $\left(\alpha<15 \mathrm{~Hz}, 16<\beta<30 \mathrm{~Hz}, 31<\gamma_{\text {low }}<60 \mathrm{~Hz}, \gamma_{\text {high }}>60 \mathrm{~Hz}\right)$.

\section{Results}

The cortical response to acoustic stimuli consists of evoked and induced components

The stereotypical electrical response of A1 neurons to a strong transient acoustic stimulus (here: $50 \mu$ s click, $40 \mathrm{~dB}$ above ABR threshold) featured a prominent primary component, both in extracellular multiunit activity (Fig. $2 A$ ) as well as trial-averaged LFPs (Fig. 2B). This first burst of activity lasted between 20-30 $\mathrm{ms}$. A second excitatory response can be observed in peristimulus time histograms with a peak latency at $\sim 150 \mathrm{~ms}$ after the stimulus. This response had strongly reduced amplitude compared with the first component. In the LFP response averaged over 30 stimulus repetitions compared with the onset response this second peak was less conspicuous and harder to distinguish from background activity. The time-frequency representation, on the other hand, revealed stimulus related activation for several 100 $\mathrm{ms}$ after the stimulus in alpha, beta, and gamma band, with a separation between the first and the second component (Fig. 2C).

The intertrial phase coherence revealed significant phase-locking with phase-locking factor values above $p_{\text {crit }}=0.3918$ (see Materials and Methods) for time points up to $100 \mathrm{~ms}$ (Fig. $3 A, B$ ). Thus a transient acoustic stimulus elicited a strong evoked excitation in the first $100 \mathrm{~ms}$. This was followed by a second period of non-phaselocked activity that is not reflected in the phase-locking factor, but revealed in total oscillatory power (Figs. 3A, 2C). For ease of discussion in what follows the primary excitatory response component will be called the "evoked response" (0-100 ms poststimulation) and the secondary, long-latency excitatory response component will be called the "induced response" (100-300 ms poststimulation), knowing that the early response contains some weak induced activity, too (Yusuf et al., 2017).

In general, the strongest response to an acoustic click was found in the supragranular layers, especially in layers 2 and 3 (Figs. 2, 3C,D), although statistical significance of the factor "recording depth" was not reached, neither for the evoked response amplitude (ANOVA, Shank 1: $F_{(5,48)}=1.71, p=0.1511$; Shank $\left.2: F_{(5,48)}=1.31, p=0.2753\right)$, nor for the induced response amplitude (ANOVA, Shank 1: $F_{(5,48)}=0.79, p=$ 0.5607; Shank 2: $\left.F_{(5,48)}=0.52, p=0.7625\right)$.

The evoked response was broadband, with peak amplitudes $>10 \mathrm{~dB}$ relative to baseline for all tested frequency bands (Fig. 3E; 


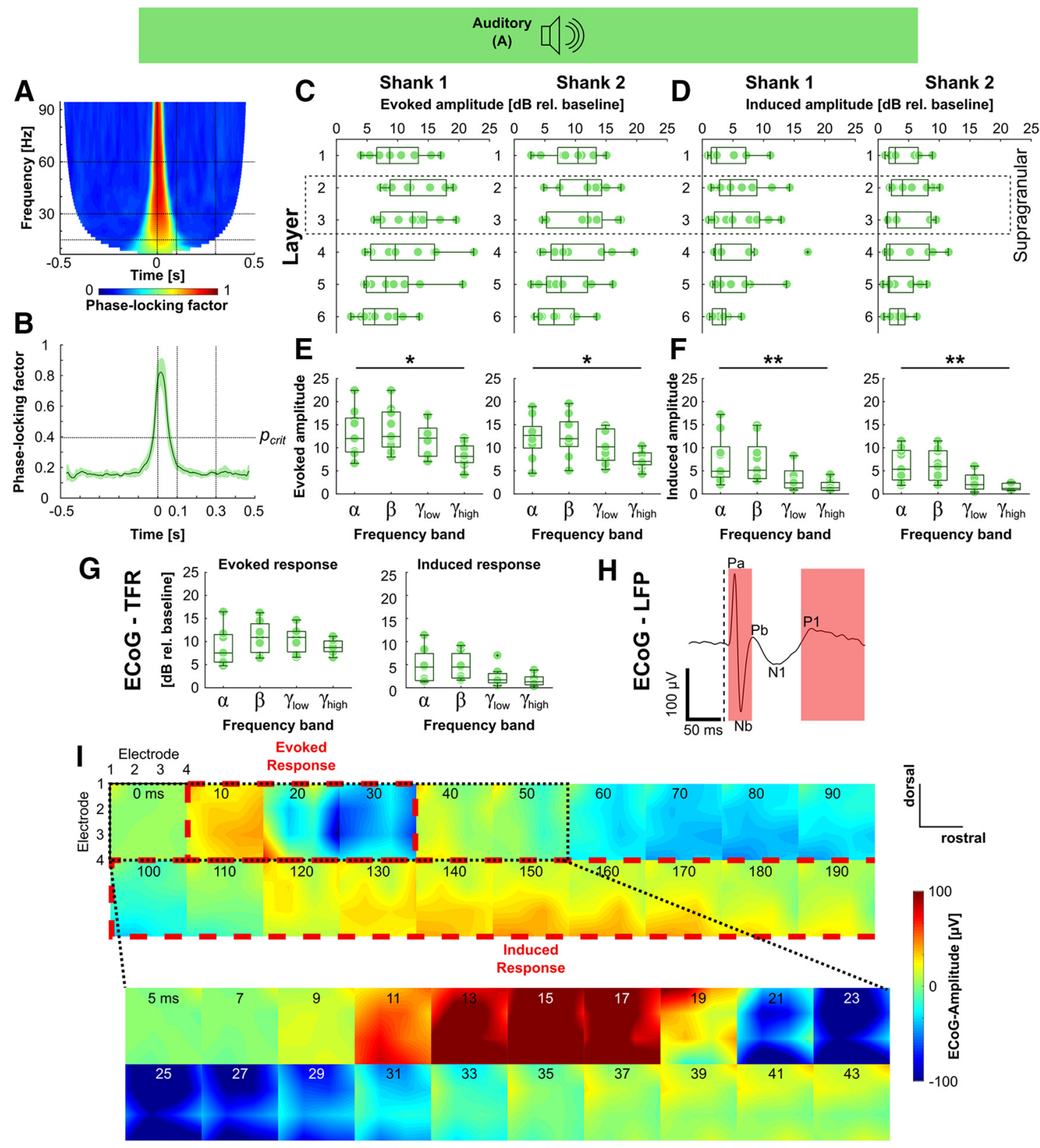

Figure 3. Quantification of the response of A1 to transient acoustic stimulation. $A$, Grand average of the intertrial phase coherence averaged over the electrodes of Shank 1. B, Collapse of the phase-locking factor over all frequencies (dark green line $=$ mean, shaded area $=S D$ ) shows that during the first $100 \mathrm{~ms}$ the intertrial phase coherence drops below the critical value for statistical significance, i.e., the early response is evoked (= phase-locked to the stimulus) and the long-latency response is induced (= non-phase-locked). $\boldsymbol{C}-\boldsymbol{F}$, Amplitude of the evoked response $(\boldsymbol{C}, \boldsymbol{E})$ and induced response $(\boldsymbol{D}, \boldsymbol{F})$ as a function of cortical layer $(\boldsymbol{C}, \boldsymbol{D})$ and frequency band $(\boldsymbol{E}, \boldsymbol{F})$ for Shank 1 (left) and Shank 2 (right) ${ }^{*} p<0.05,{ }^{* *} p<0.01$. $\boldsymbol{G}$, Amplitude of the evoked response (left) and induced response (right) calculated from the time-frequency response of 16 surface electrodes. $\boldsymbol{H}$, Example trace of the low-pass filtered ECOG signal (ECOG-LFP) in response to acoustic stimulation showing the same time course as depth recordings. I, Spatial plots of ECOG-LFP amplitude at different time points. The click stimulus evoked a widespread biphasic response between 10 and 35 ms after the stimulation, followed by a slow negative component and a weaker, spatially more inhomogeneous long-latency positive component.

ANOVA, Shank 1: $F_{(3,32)}=3.14, p=0.0387$; Shank 2: $F_{(3,32)}=$ $3.56, p=0.0249)$, whereas the induced response showed a concentration in the lower frequencies in the alpha $(<15 \mathrm{~Hz})$ and beta $(15-30 \mathrm{~Hz})$ range (Fig. 3F; ANOVA, Shank 1: $F_{(3,32)}=4.63$, $p=0.0084$; Shank 2: $\left.F_{(3,32)}=6.69, p=0.0012\right)$, with additional brief gamma transients.

The time-frequency analysis of electrocorticographic (ECoG) surface recordings showed the same frequency pattern as recordings from the depth of the cortex, but with somewhat lower amplitudes and larger inter-experimental variance (Fig. 3G; ANOVA, evoked response: $F_{(3,24)}=0.74, p=0.538$; induced response: $F_{(3,24)}=2.36$, $p=0.0967)$. The low-pass filtered, time-domain ECoG potential
(ECoG-LFP) followed the pattern of the intracortical recordings, with a transient biphasic primary excitation and a lower amplitude secondary response (Fig. $3 H$ ). Given the broad-frequency acoustic click stimulation and the surface electrode being located on A1, the potential distribution over the different surface electrodes was relatively even (Fig. 3I), indicating a homogenous activation of the primary auditory cortex.

\section{Low-current ICMS elicits the evoked but not the induced response component}

Applying a single, biphasic, charge-balanced ICMS current pulse of moderate strength ( $3 \mu \mathrm{A}, 200 \mu$ s phase duration) on one of the 


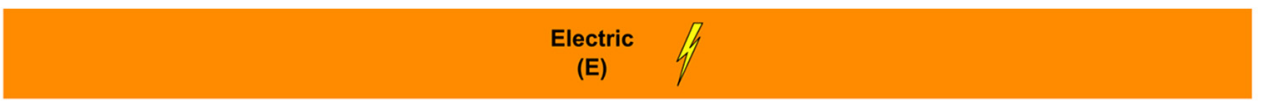

A
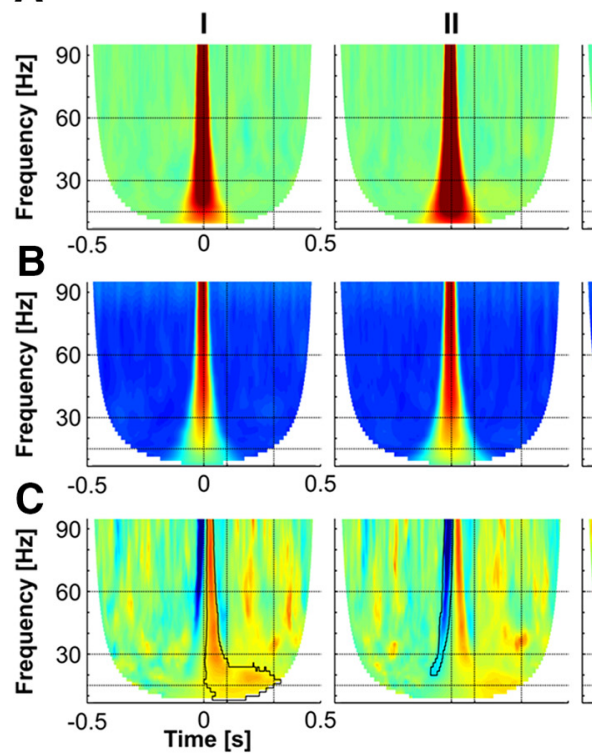

D $45 \mu \mathrm{A}$ - Example

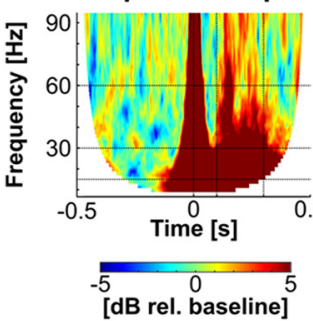

E

Evoked amplitude

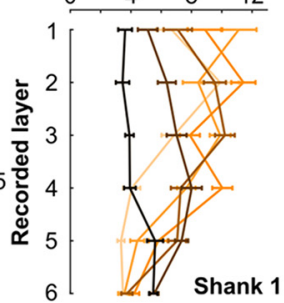

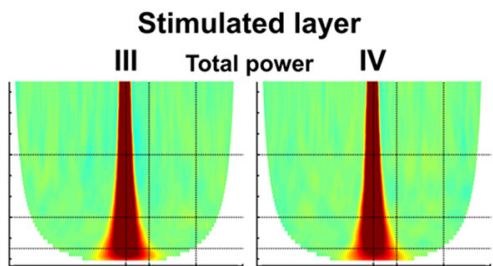

III Total power
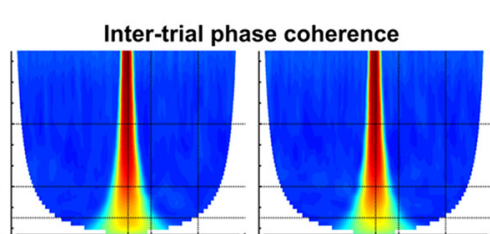

Cluster-based permutation test
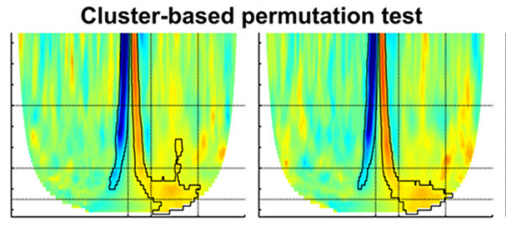
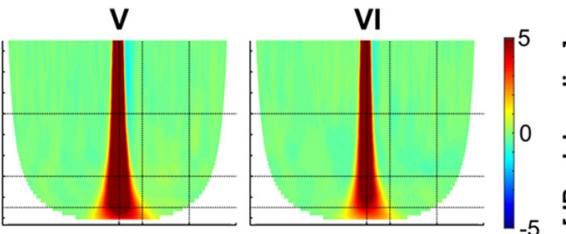

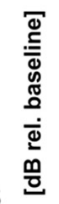
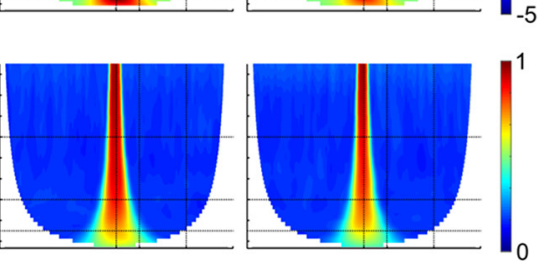

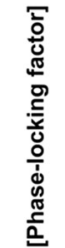

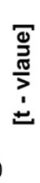

9
$\frac{\pi}{2}$
+

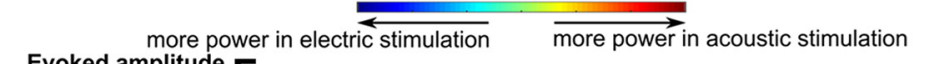

Evoked amplitude $F$

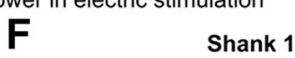

Shank 2
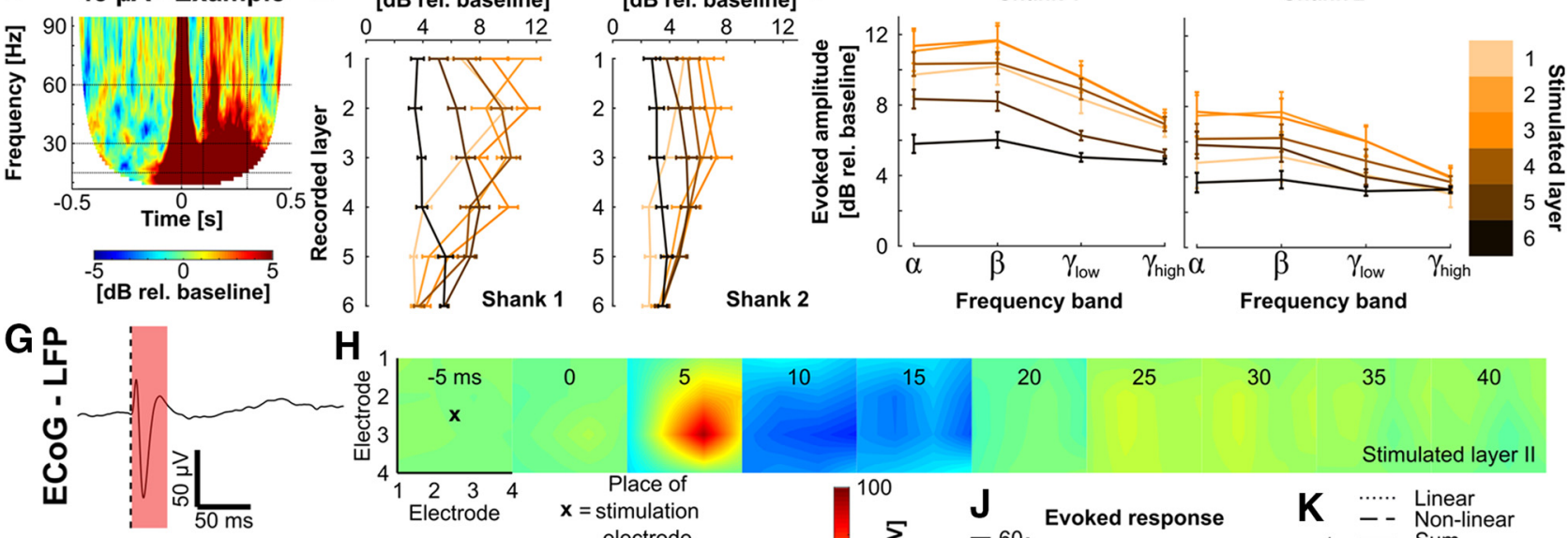

$\mathrm{H}_{1}$
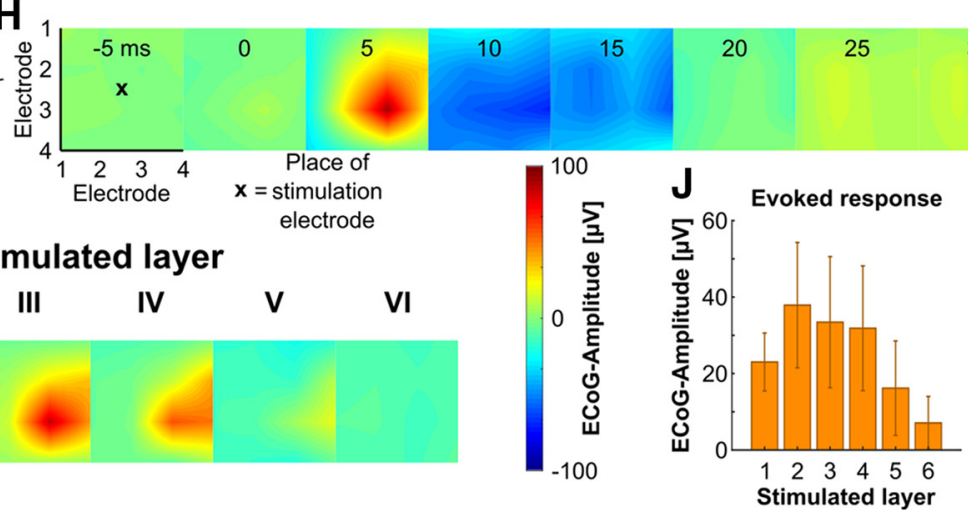

30

35

40

Stimulated layer II

I

Stimulated layer

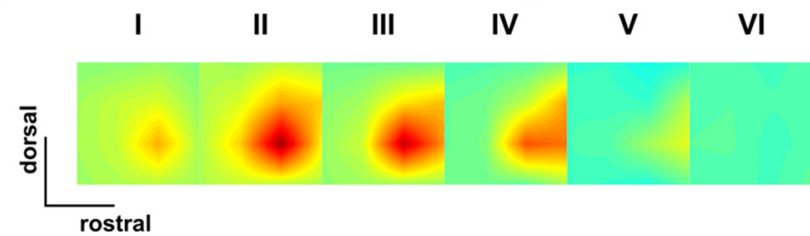

Stimulated layer

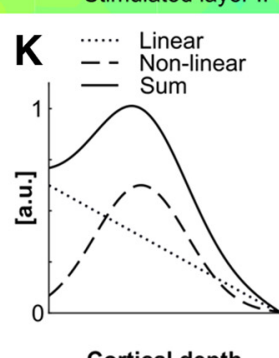

Figure 4. Response of A1 to intracortical microstimulation. $A$, Grand average of total power (Shank 1) for electrical stimulation in each cortical layer. B, Grand average of intertrial phase coherence (Shank 1 ) for electrical stimulation in each cortical layer. $\boldsymbol{C}$, Cluster-based permutation test for statistically significant differences between responses to acoustic stimulation and electric stimulation in each layer (black contour $=$ statistically significant clusters, $p<0.05$ ). Warm colors (yellow/orange) signify more power in the auditory condition; cool colors (blue) signify more power in the electric condition. $D$, Single example of the time-frequency representation of activity evoked by electric-only stimulation with $45 \mu \mathrm{A}$. Data from a separate animal, recording electrode in layer 2, ICMS in layer 1 . $\boldsymbol{E}$, Evoked response amplitude (mean \pm SEM) as a function of recorded layers for electrodes on Shank 1 (left) and Shank 2 (right). See $\boldsymbol{F}$ for color code. $\boldsymbol{F}$, Evoked response amplitude (mean \pm SEM) as a function of frequency band for Shank 1 (left) and Shank 2 (right). Different shades of orange mark different stimulated layers. G, Example trace of the ECoG-LFP signal in response to ICMS. Only the early evoked response is visible. $\boldsymbol{H}$, Spatial plots of the grand mean of ECoG-LFP response amplitude at different time points ( $x=$ approximate position of the stimulation electrode). I, Spatial plot of the grand mean of peak ECoG-LFP response in the $50 \mathrm{~ms}$ poststimulation for ICMS in each cortical layer. J, Quantification of peak evoked response amplitude (mean \pm SEM) for stimulation in each layer. $\boldsymbol{K}$, Approximation of observed ECoG amplitudes (a.u.) for stimulation in different cortical depths as the sum of a linear and nonlinear model equation with arbitrarily chosen parameters, representing the distance of a dipole from the surface and the effectivity of ICMS as a function of cortical depth respectively (for a detailed explanation, see Results).

electrodes of the linear multielectrode array and recording from the other cortical electrodes (31 depth electrodes and 16 surface ECoG electrodes) showed cortical activity comparable to the response to acoustic stimulation. As with transient acoustic stim- ulation, a single electric pulse evoked a strong excitatory broadband response in the first $100 \mathrm{~ms}$ following stimulation, as seen in the time-frequency representation of total power (Fig. 4A) and intertrial phase coherence (Fig. $4 B$ ). In contrast to the natural, 
acoustic stimulation, however, low-current ICMS did not induce any long-latency response. This was independent of the layer of electrical stimulation. Cluster-based permutation tests between the total power time-frequency representations of acoustic and electric stimulation confirmed the significantly smaller amplitude of the induced response when stimulating electrically (Fig. $4 C)$. The observed statistical differences in the evoked response time window show the effect of the different response latencies to acoustic and electrical stimulation: the evoked response had shorter latencies during ICMS trials compared with acoustic stimulation. Only higher current ICMS $(\sim 45 \mu \mathrm{A}, 200 \mu$ s phase duration) than used for the results here, is able to generate longlatency (induced) response components (Fig. 4D).

The low-current ICMS evoked amplitude was highest at or next to the layer of stimulation (Fig. $4 E$ ). Similar to the acoustic response, the electric response had the largest power in the alpha and beta band (Fig. 4F). Furthermore the evoked response amplitude dropped with increasing distance to the site of stimulation. Highest amplitudes were consistently recorded on Shank 1, which contained the stimulation electrode. The ECoG-LFP response showed only a first transient excitation and no longlatency components (Fig. 4G), but in contrast to the acoustic response the mean of the surface response was spatially distinct (Fig. $4 H$ ). In the grand mean over all experiments, peak response amplitudes were located next to the stimulating electrode position. Electrical stimulation in different depths resulted in different peak amplitudes according to the stimulated layer (Fig. 4I). Highest response amplitudes could be recorded from the surface when stimulating layer 2 (Fig. $4 J$ ). We hypothesize that the specific potential amplitude recorded from the surface in response to intracortical electric stimulation is the result of two separate processes. First, the amplitude of the potential recorded from the cortical surface decreases with increasing distance of the generating dipole (= neuronal activity) from the cortical surface. Second, the evoked potential amplitude in response to intracortical microstimulation shows a nonlinear relationship with stimulation depth (Voigt et al., 2017). Consistent with these prior results, ICMS has shown highest response amplitudes when stimulating the middle layers. A simple model for a superposition of these two effects: a sum of a linear and a nonlinear component (Fig. 4K) closely matches the observed depth profile recorded from the surface of the cortex (Fig. 4J).

\section{Combined stimulation enhances the induced response component}

Next, acoustic (A) and electric (E) stimulation has been combined $(\mathrm{A} \& \mathrm{E})$ with a delay $(\Delta t)$ of 5,15 , or $25 \mathrm{~ms}$ between $\mathrm{A}$ and $\mathrm{E}$ stimulation onset (Fig. 1C). This results in a focused electric pulse either directly before $(\Delta t=5 \mathrm{~ms})$, at $(\Delta t=15 \mathrm{~ms})$, or after $(\Delta t=$ $25 \mathrm{~ms}$ ) the peak of the acoustically evoked activity in A1 (Fig. 7A). Because in the A condition responses were generally strongest in supragranular layers (Fig. 3C,D), analyzes of A\&E responses were restricted to recording electrodes situated in layers 2 and 3.

The combined A\&E stimulation resulted in time-frequency response patterns that followed the physiological, acoustic stimulation but with higher amplitudes (Fig. 5A). The intertrial phase coherence showed a similar function as with acoustic stimulation, i.e., the phase-locking factor dropped below the critical level after the first $100 \mathrm{~ms}$ poststimulation (Fig. $5 B, C$ ).

There was a strong evoked response with significant, independent influences of both the electrically stimulated layer and the time delay between A and E stimulation on the evoked response amplitude recorded from the supragranular layers of the stimu- lated shank (two-way ANOVA; fixed-factor "layer": $F_{(5,144)}=$ $162.42, p<0.0001$; random factor "delay": $F_{(2,10)}=9.68, p=$ 0.0046 ; interaction: $\left.F_{(10,161)}=0.05, p>0.9999\right)$. The influence of the electrically stimulated layer on the evoked response amplitude followed previous results (Voigt et al., 2017): the highest response amplitude was achieved by stimulating the superficial layers, including the top-down feedback receiving layer 1 and the thalamo-recipient layer 4 (Fig. 5D). Concerning the different stimulus delays, the highest response amplitudes were reached at a delay of $15 \mathrm{~ms}$ between the acoustic and the electric pulse. In contrast to either A or E stimulation alone, which both showed most power in the alpha and beta frequency band, combined A\&E stimulation showed most power in the high gamma (60-95 $\mathrm{Hz}$ ) band (Fig. 5E).

To be able to judge whether the increased response amplitude in A\&E stimulation resulted from an increase in stimulation intensity ( 2 stimuli being presented in combined stimulation, instead of only 1 as in each single modality), we calculated the difference component. The responses (time-frequency representations of total power in decibel relative to baseline) to each type of stimulation (acoustic A, electric E) were linearly added and the resulting sum was subtracted from the combined stimulation (A\&E; Fig. 5A):

$$
\text { Difference }=\mathrm{A} \& \mathrm{E}-(\mathrm{A}+\mathrm{E}) \text {. }
$$

This difference shows supra-additive effects due to ICMS as positive values, and sub-additive effects as negative values. Significant deviations from zero violate the condition of additivity of the superposition principle and therefore supra-additive and subadditive interactions can be considered nonlinear.

The peak difference in the time-window of the induced response revealed two separate groups of experiments $(\Delta t=5 \mathrm{~ms}$, averaged over all stimulation depths and frequencies; Fig. $5 F$ ). One group, consisting of four experiments (45\% of all experiments), showed a pronounced supra-additive enhancement of the induced response due to electric stimulation, and was labeled "super-additive" here. The other group (the remaining 5 experiments) lacked this nonlinear super-additive effect on the longlatency responses and the interaction was classified as "neutral" (but was in supra-additive interaction range). A $k$-means clustering $(k=2)$ confirmed the separation with cluster means of 11.82 and 5.49, respectively. The peak induced response in the acoustic only condition showed that the 4 experiments, which were classified as super-additive in response to the combined stimulation, were experiments with the strongest induced response (Fig. 5F). That is, experiments in which acoustic stimulation led to a strong induced response were most likely to show super-additive effects when the electrical stimulus was added. This is reasonable because the electrical influence on the induced response may be the consequence of the extent of its generation by the previous acoustic stimulus.

In the experiments categorized as super-additive, an interesting dissociation between evoked and induced responses was noted: in the evoked component the combination of acoustic and electric stimulation, with a delay of $5 \mathrm{~ms}$ (Fig. 6A), $15 \mathrm{~ms}$ (Fig. $6 B$ ), or $25 \mathrm{~ms}$ (Fig. $6 \mathrm{C}$ ), resulted in a sub-additive response, whereas the induced response was super-additive. Supra-additive effects in the evoked response time window, visible as a brief red band in the gamma range directly before (Fig. 6A) or after (Fig. $6 B, C)$ the sub-additive region, are a consequence of the temporal shift of the peak of activity in consistence with the electrical stimulus delay. 


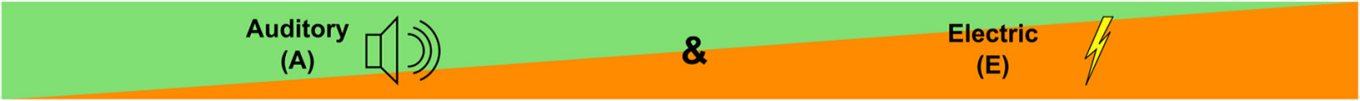

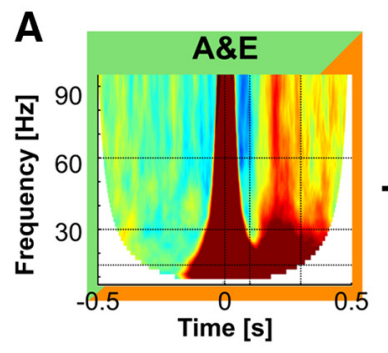

B

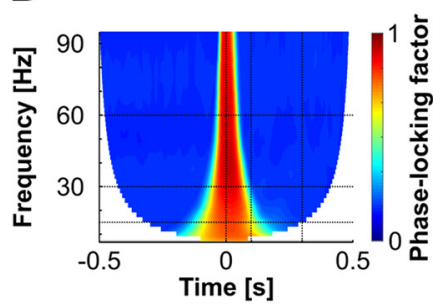

C

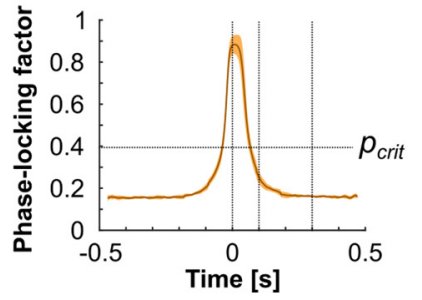

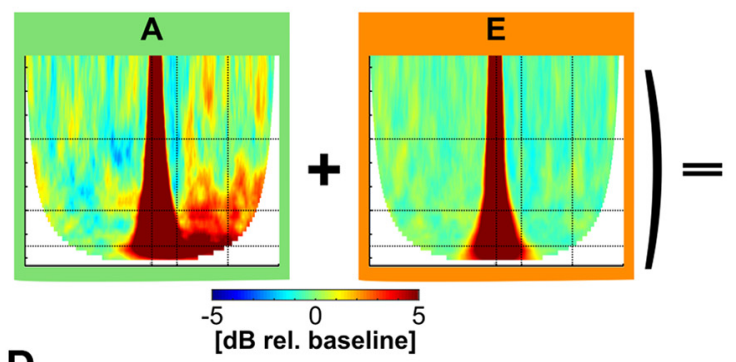

Shank 1

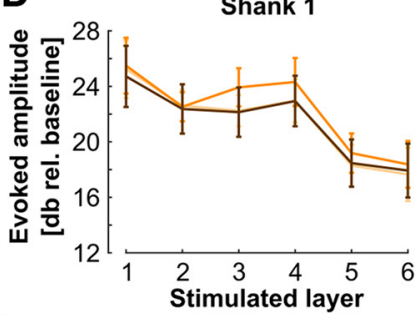

E

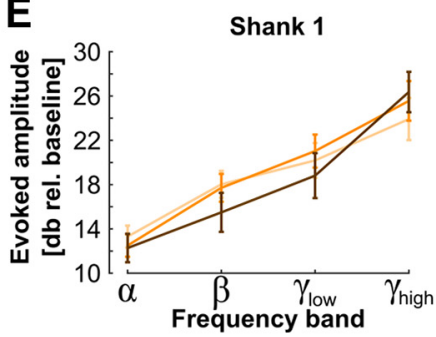

Shank 2
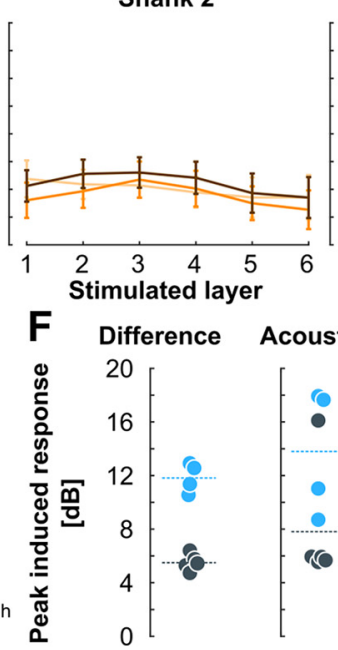

Difference

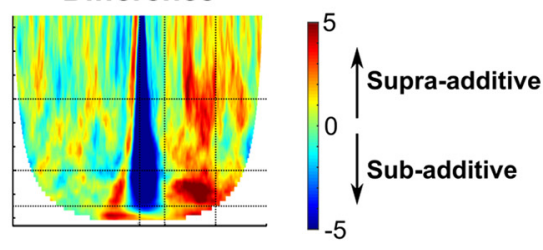

Figure 5. Response of $A 1$ to combined acoustic and electric stimulation. $A$, Example of total power, average of the supragranular electrodes of Shank 1 , for combined auditory and electric stimulation ( $A \& E$, left), acoustic stimulation alone ( $A$, middle left), electric stimulation alone ( $E$, middle right), and the difference between those (right), calculated as $A \& E-(A+E)$. $\boldsymbol{B}$, Grand mean of phase-locking factor for combined stimulation, average of all electrodes of Shank 1 and all stimulated layers at $\Delta t=5$ ms. $C$, Phase-locking factor collapsed over frequencies. Responses up to 100 ms poststimulation were statistically phase-locked ( $=$ evoked, dark orange line $=$ mean, shaded area $=$ SD). $\boldsymbol{D}$, Evoked response amplitude (mean \pm SEM) for combined stimulation as a function of stimulated layer for electrodes of Shank 1 (left), Shank 2 (middle), and from the surface (ECoG, right). Different colored lines mark different time delays between acoustic and electrical stimulus. $\boldsymbol{E}$, Evoked response amplitude (mean \pm SEM) as a function of frequency band for electrodes of Shank 1 . For color code see $\boldsymbol{D}$. $\boldsymbol{F}$, Peak of induced response of the calculated difference for a delay of $5 \mathrm{~ms}$ (left) and auditory only stimulation (middle). Each dot represents a single experiment (blue = super-additive, dark gray = neutral). Stacked bar chart showing the percentage of experiments classified as super-additive (right).

Peak differences in the induced response time window (superadditive experiments, Shank 1) were statistically analyzed with respect to the three factors: stimulated layer, ICMS pulse delay, and analyzed frequency band. There were no significant effects of the main factors (three-way ANOVA, fixed-factor layer: $F_{(5,10)}=$ $0.17, p=0.9665$; random factor "delay": $F_{(2,5.15)}=0.37, p=$ 0.7057 ; fixed-factor frequency band: $\left.F_{(3,6)}=3.11, p=0.1099\right)$, or the interactions between the factor layer and the ICMS pulse delay ("layer $\times$ delay": $F_{(10,30)}=0.87, p=0.5685$ ), and layer and the frequency band ("layer $\times$ frequency band": $F_{(15,30)}=0.90$, $p=0.5734$ ). But the interaction between the ICMS pulse delay and the frequency band ("delay $\times$ frequency band": $F_{(6,30)}=$ 3.07, $p=0.0182)$ and the three-way interaction between all three factors ("layer $\times$ delay $\times$ frequency band": $F_{(30,216)}=4.30, p<$ 0.0001 ) were significant.

Furthermore, the peak difference in the induced response time window was statistically tested against the hypothesis that the observed values are drawn from a distribution with a mean of 0 using one-sample $t$ tests. Because of the absence of main effects of the factors ICMS pulse delay (Fig. 6D), stimulated layer (Fig. $6 E$ ) and frequency band (Fig. $6 F$ ) on the induced response amplitude difference in the pooled three-way ANOVA analysis, each one of these factors was examined separately (Table 1). Even after correcting for multiple comparisons (Benjamini-Hochberg procedure), all group means were significantly different from 0 . This confirms the presence of a supra-additive enhancement of longlatency induced responses to a combination of acoustic and electric stimulation.

\section{ICMS responses were integrated into ongoing cortical processing}

To determine whether the activity elicited by the electrical stimulus was integrated into the cortical processing of the acoustic stimulus or substituted the ongoing activity, we analyzed the trial-to-trial variability of the cortical response amplitudes and its dependence on the phase of the LFP at the time of stimulation. We used the phase of the wideband LFP as an extracellular electrical representation of the instantaneous network state. Because a peripheral (here: acoustic) stimulus locks the phase of the LFP for $\sim 50$ ms poststimulation to a specific value (Fig. $3 A, B$ ), additionally presenting an electrical stimulus with a fixed delay $(\Delta t)$ to the acoustic stimulus ensures that the electrical stimulation occurs during a specific network state (Fig. 7A).

The instantaneous network state $(=$ phase $)$ at the time of stimulation is a predictor of the cortical response amplitude in a single trial. We compared, for all electrodes separately, the LFP 
Difference: A\&E - ( A + E )

A
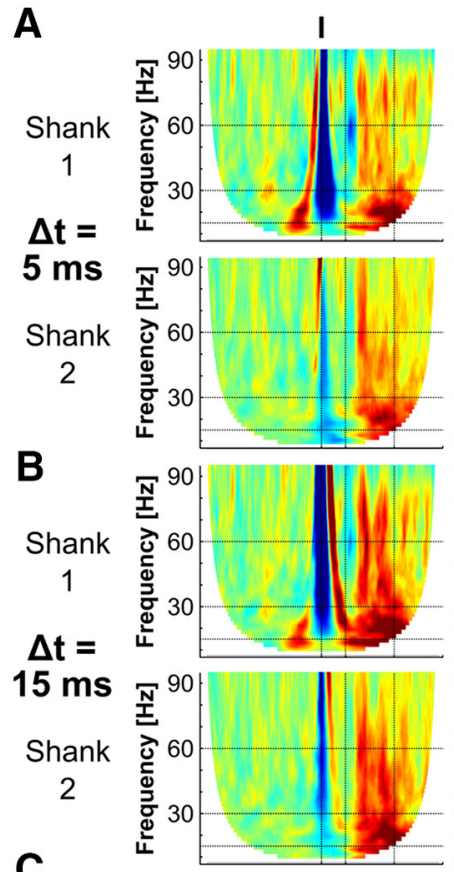

C

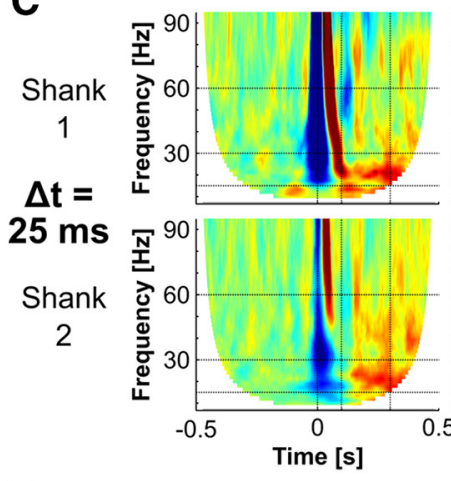

D

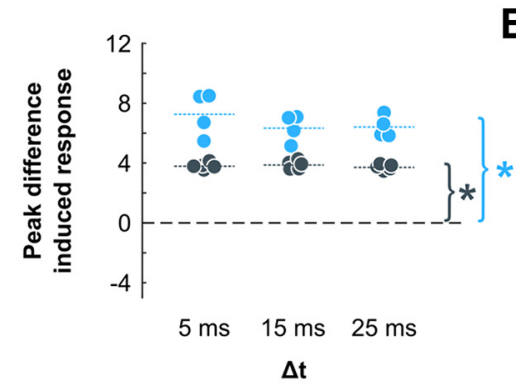

II
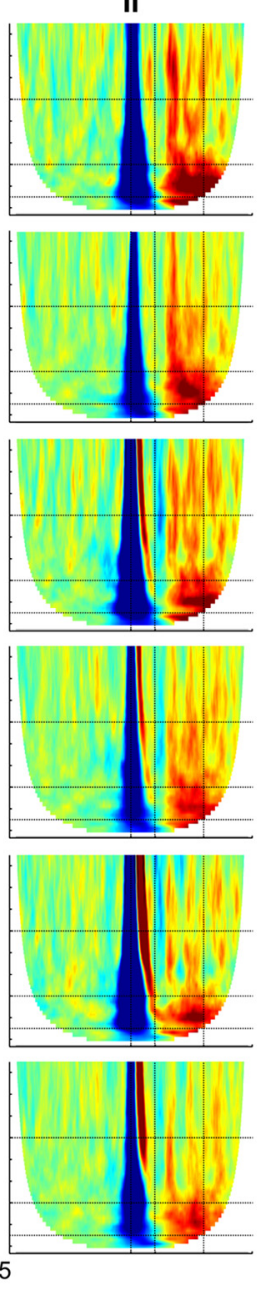

Stimulated layer
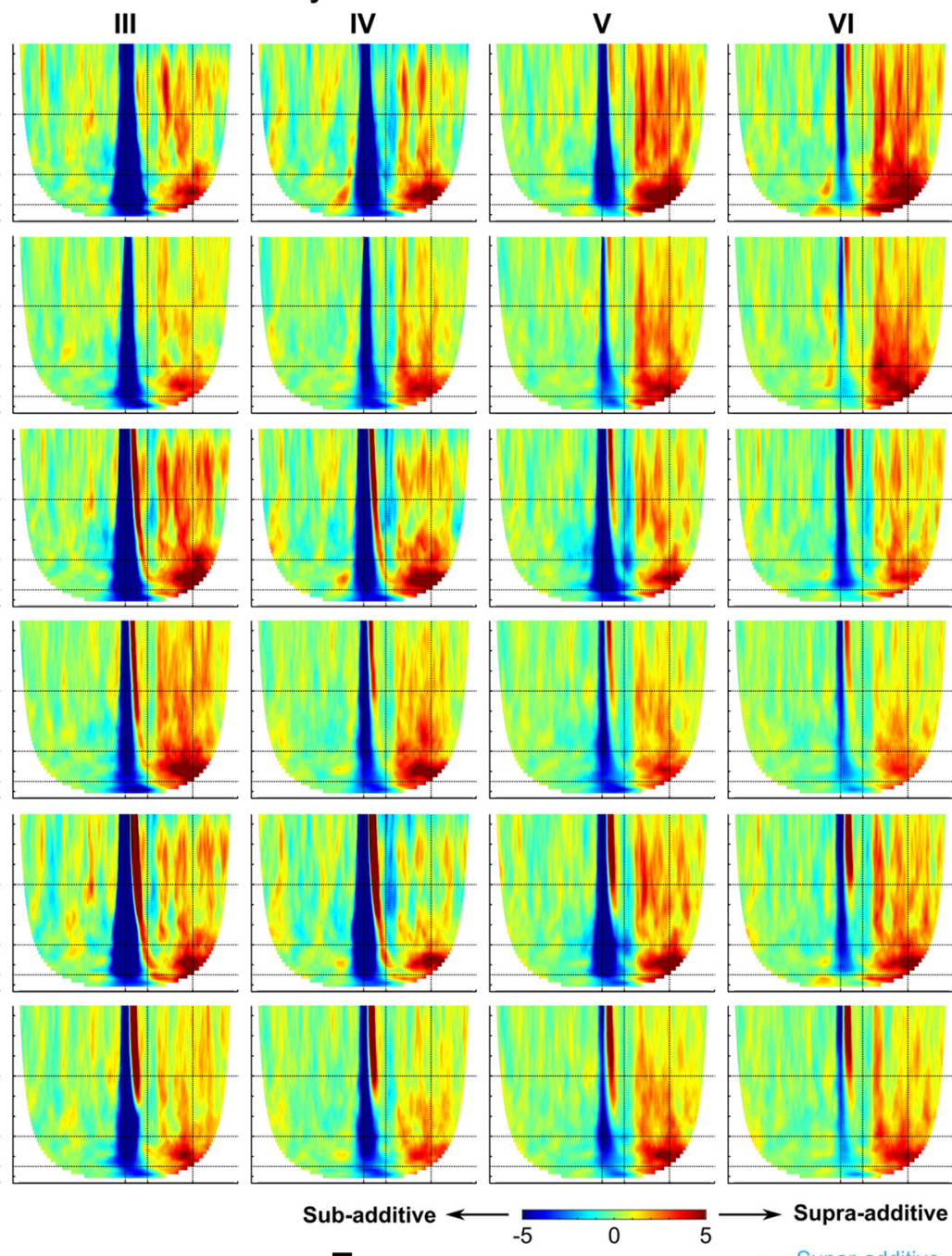

E

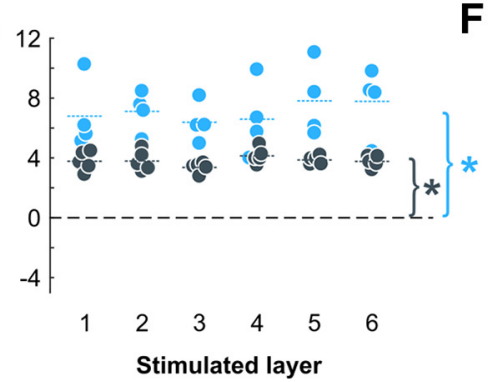

$\mathbf{F}$
- Super-additive

Mean

- Neutral

Mean

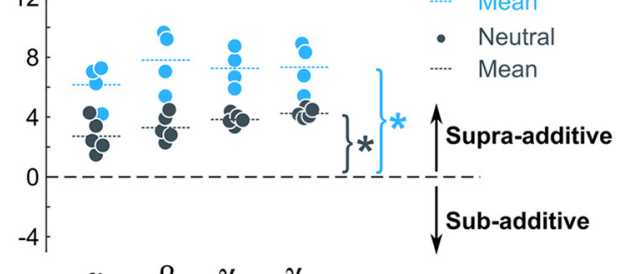

$\alpha \quad \beta \quad \gamma_{\text {low }} \gamma_{\text {high }}$

Frequency band

Figure 6. Combined acoustic and electric stimulation shows supra-additive enhancement of long-latency induced responses. $A$, Grand mean of the difference (supragranular recording electrodes, supra-additive experiments) for stimulation in each cortical layer with a delay of $5 \mathrm{~ms}$, for Shank 1 (top row), and Shank 2 (bottom row). $\boldsymbol{B}$, Same as $\boldsymbol{A}$, but for $\Delta t=15 \mathrm{~ms}$. $\boldsymbol{C}$, Same as $\boldsymbol{A}$, but for $\Delta t=25 \mathrm{~ms}$. $\boldsymbol{D}-\boldsymbol{F}$, Peak induced difference (supragranular electrodes, Shank 1$)$ as a function of stimulation delay (D), stimulated layer $(\boldsymbol{E} ; \Delta t=5 \mathrm{~ms})$, and frequency band $(\boldsymbol{F} ; \Delta t=5 \mathrm{~ms})$. Each dot represents a single experiment (blue $=$ super-additive, dark gray $=$ neutral). ${ }^{*} p<0.05$ for one-sample $t$ tests showing statistically significant differences from 0 .

phase at different time points $(\Delta \varphi)$ before stimulation with the evoked peak amplitude in a given trial. At $\Delta \varphi=-300$, i.e., at 300 ms before stimulus onset, the LFP phase was not predictive of the evoked response amplitude in acoustically stimulated trials (Fig. $7 B)$. However, at $\Delta \varphi=0$, i.e., at the time of stimulus onset, the response amplitude depended on the phase of the local field potential, with amplitudes being highest for trials in which the field potential was in the falling phase at the time of acoustical stimulation. The same dependence was shown in electrically stimulated trials (Fig. 7C), speaking for an influence of ongoing activity on the response amplitude and thus a "natural" integration of electrically conveyed activity into the prestimulus network processing. We quantified this influence of the prestimulus phase as modulation index (see Materials and Methods). This modulation index revealed that the prestimulus phase started to become predictive of the single trial amplitude from $\sim 25 \mathrm{~ms}$ before the stimulus in acoustically stimulated trials (Fig. $7 D$ ), to $50 \mathrm{~ms}$ before the stimulus in electrically stimulated trials (Fig. 7E). This corre- 
Table 1. Induced response amplitude is supra-additive in combined acoustic and electric stimulation

\begin{tabular}{|c|c|c|}
\hline & \multicolumn{2}{|l|}{$p$ values } \\
\hline & Super-additive & Neutral \\
\hline \multicolumn{3}{|l|}{ Delay, ms } \\
\hline 5 & $0.0022^{* *}$ & $<0.0001^{* * *}$ \\
\hline 15 & $0.0008^{* * *}$ & $<0.0001^{* * *}$ \\
\hline 25 & $0.0004^{* * *}$ & $<0.0001^{* * *}$ \\
\hline \multicolumn{3}{|c|}{ Stimulated layer } \\
\hline 1 & $0.0103^{*}$ & $0.0002^{* * *}$ \\
\hline 2 & $0.0019^{* *}$ & $0.0002^{* * *}$ \\
\hline 3 & $0.0024^{* *}$ & $<0.0001^{* * *}$ \\
\hline 4 & $0.0130^{*}$ & $0.0001^{* * *}$ \\
\hline 5 & $0.0080^{* *}$ & $<0.0001^{* * *}$ \\
\hline 6 & $0.0067^{* *}$ & $<0.0001^{* * *}$ \\
\hline \multicolumn{3}{|c|}{ Frequency band } \\
\hline$\alpha$ & $0.0031^{* *}$ & $0.0054^{* *}$ \\
\hline$\beta$ & $0.0043^{* *}$ & $0.0011^{* *}$ \\
\hline$\gamma_{\text {low }}$ & $0.0014^{* *}$ & $<0.0001^{* * *}$ \\
\hline$\gamma_{\text {high }}$ & $0.0026^{* *}$ & $<0.0001^{* * *}$ \\
\hline
\end{tabular}

Statistical results for one-sample $t$ tests, testing against the hypothesis that response amplitudes are drawn from a distribution with a mean of 0 ; Benjamini-Hochberg correction for multiple testing did not exclude any test result. ${ }^{*} p<0.05,{ }^{* *} p<0.01,{ }^{* * *} p<0.001$.

sponds to an oscillatory frequency of 40 and $20 \mathrm{~Hz}$, respectively. In acoustically stimulated trials, the modulation index (the influence of prestimulus phase) was highest in supragranular layers (Fig. $7 F$ ). In electrically stimulated trials, the modulation index followed the place of stimulation; with the phase at the electrodes of the stimulated layer being the most predictive of the stimulus amplitude (Fig. $7 G$ ). In A\&E combined stimulated trials, the modulation index, calculated using the total power in the lowgamma band $(30-60 \mathrm{~Hz})$ during the evoked response time window, followed the acoustically stimulated pattern. The strongest phase influence was found in the supragranular layers, regardless of electrical stimulation depth (Fig. $7 H$ ). The dependence on the prestimulus time-point used to calculate the modulation index also followed the pattern of the acoustically stimulated trials (Fig. $7 I)$. The delay of the electrical stimulus $(\Delta t)$ had no influence on this phase dependence. The low-gamma power of the induced response showed the same prestimulus phase dependence as the evoked response (Fig. $7 J$ ). This dependence on network state shows that the response to combined stimulation integrates into ongoing cortical processing in a similar way as natural acoustic stimulation, confirming the potential for modulatory action of the low-current electrical stimulus.

\section{Discussion}

In the present study we found that applying low-current microstimulation pulses inside the auditory cortex during the processing of an acoustic stimulus differentially modulates the cortical response. Whereas evoked responses were sub-additively combined, induced responses showed a nonlinear, supra-additive enhancement of oscillatory activity. The amplitudes of all observed responses were influenced by the ongoing activity preceding the stimulus. Thus, instead of artificially substituting (resetting) the ongoing cortical processes, the activity elicited by electrical stimuli was integrated into concurrent cortical activity in a similar manner as activity in response to peripheral stimuli. The largest modulations were observed in animals with the largest induced activity. Combined with the distribution of induced activity (Buffalo et al., 2011; Xing et al., 2012a; Fig. 3C) this suggests that the most favorable site for such effects are supragranular layers.
All experiments reported herein were performed with the animal under general anesthesia. However, the structure of evoked and induced components is observed in both awake and anesthetized state (cf. Dimitrijevic et al., 2017 for an awake human preparation and Yusuf et al., 2017 for anesthetized cats). Furthermore, both local field potentials and their time-frequency resolved activity, as described here, are generally similar in anesthetized and awake animals (De Ribaupierre et al., 1972; Castro-Alamancos and Connors, 1996; Xing et al., 2012b). Influences of anesthesia on guinea pig A1 specifically involve for example a reduction in spike-timing precision (Huetz et al., 2009), and a reduction of response amplitude (Syka et al., 2005). Therefore, awake, attentive state would likely increase the induced activity and would thus further boost the substrate of the effects reported herein.

Electrical stimulation studies supported long-range feedback mechanisms as the basis for the long-latency induced response components. Electrical stimulation of the thalamus reliably induced long-latency gamma oscillations in the auditory cortex (Metherate and Cruikshank, 1999; Sukov and Barth, 2001). But cortical electrical stimulation in vitro (Metherate and Cruikshank, 1999) or in the chronically isolated cortex (Creutzfeldt et al., 1966) failed to induce long-latency response components. Both of those preparations lack the anatomical connections necessary for long-range interactions.

In vivo, however, "after-discharges" have been observed in response to cortical electrical stimulation in anesthetized cats (Creutzfeldt et al., 1966), albeit at higher currents than used in the present study. As Maldonado and Gerstein (1996) point out, the incidence of after-discharges in the auditory cortex is related to the intensity of acoustic stimuli. Our results suggested that this might also hold true for electrical stimulation, as an exemplary TFR of ICMS at $45 \mu \mathrm{A}$ (Fig. 4D) shows that higher intensity stimulation is indeed able to induce long-latency responses. Here we could not compare different stimulation currents directly (but see Voigt et al., 2017). Assuming that the principle of inverse effectiveness described in multisensory integration (Ghazanfar et al., 2005, Lakatos et al., 2007) holds also for acoustic-electric integration, the low-intensity current pulse used in this study might have been near the optimum of effectiveness for the amplitude of the integration effect. The most direct evidence for a link between top-down feedback signals and long-latency responses came from Klink et al. (2017), who have shown a longlatency suppression in the primary visual cortex in response to (strong) electrical stimulation of higher-order visual field V4.

In the present study, there was a supra-additive enhancement of the long-latency (induced) responses. This might be considered equivalent to the response increase in primary areas due to top-down feedback signals from higher-order areas. The electrical stimulation in this regard thus mimics gain increasing cognitive effects like attention (Fritz et al., 2007; Poort et al., 2012; Lakatos et al., 2013) or temporal expectations (Rohenkohl et al., 2012). These effects also lead to an increase of neuronal responses in primary auditory cortex (Jaramillo and Zador, 2011). Conversely, silencing higher-order areas by cooling showed a decrease in response amplitude in the respective primary area (Hupé et al., 1998; Carrasco and Lomber, 2009).

The observed supra-additive enhancement could be related to cortical plasticity. Plasticity mechanisms like spike-timingdependent plasticity, i.e., Hebbian learning have been proposed (Lebedev and Ossadtchi, 2018) and described in response to repeatedly stimulating a cortical area electrically (Jackson et al., 2006; Rebesco et al., 2010; Seeman et al., 2017). But because each combination of stimulation electrode and stimulus delay was 
A

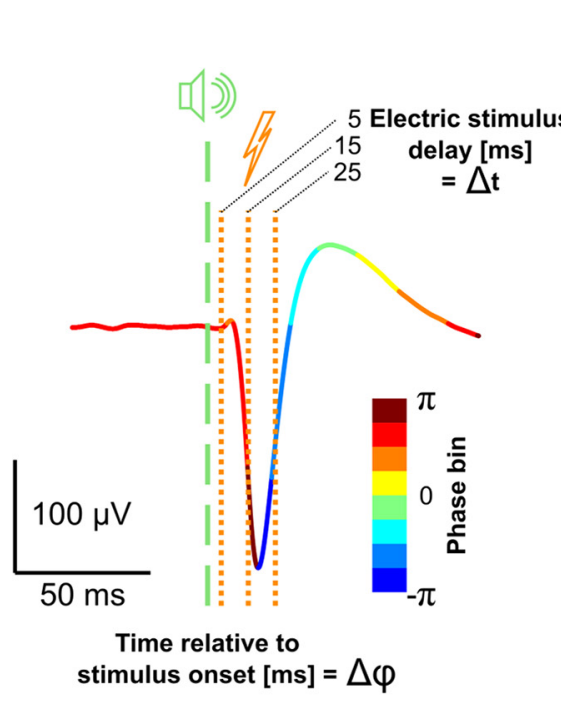

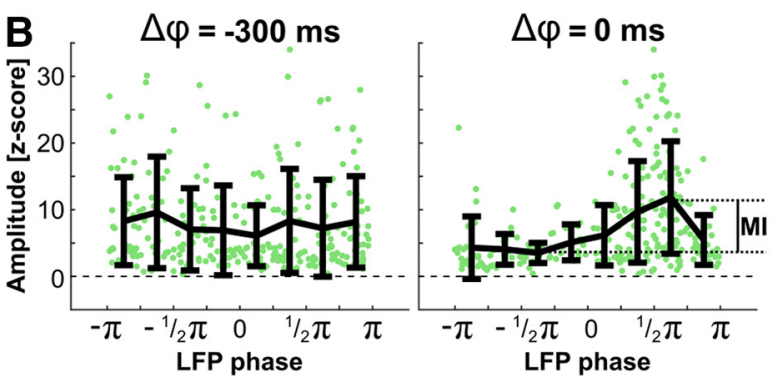

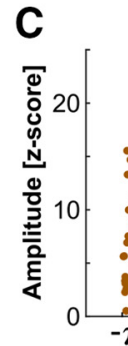

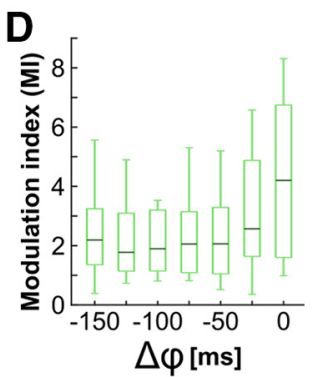

E
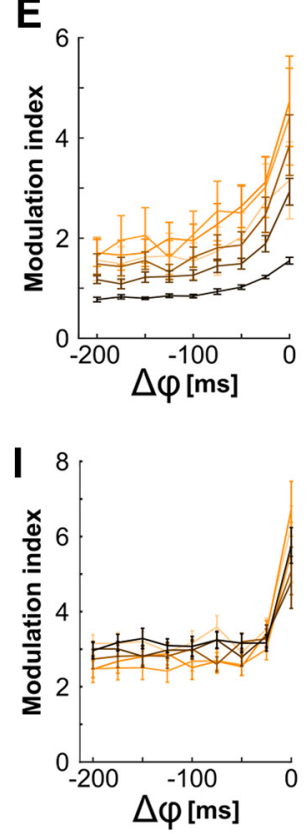

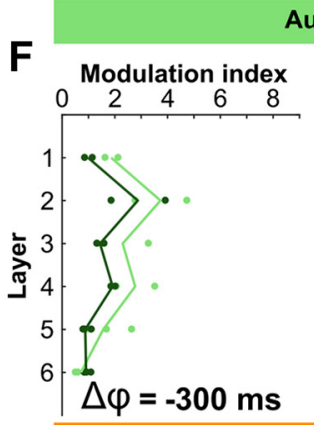

Auditory 미)

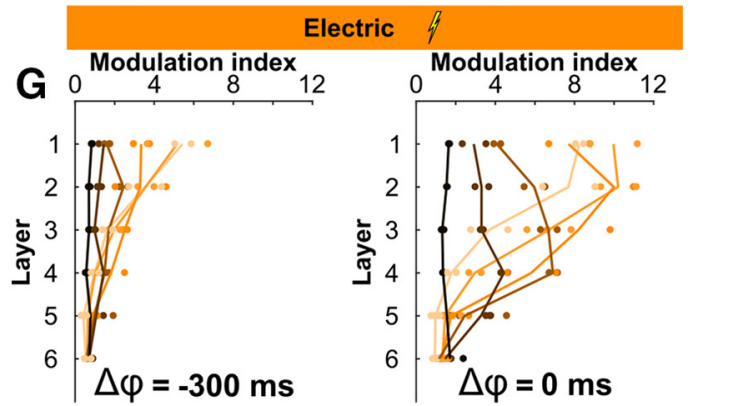

\& Electric

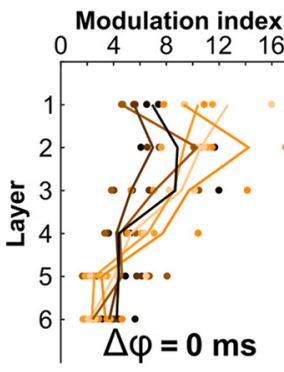

Induced response
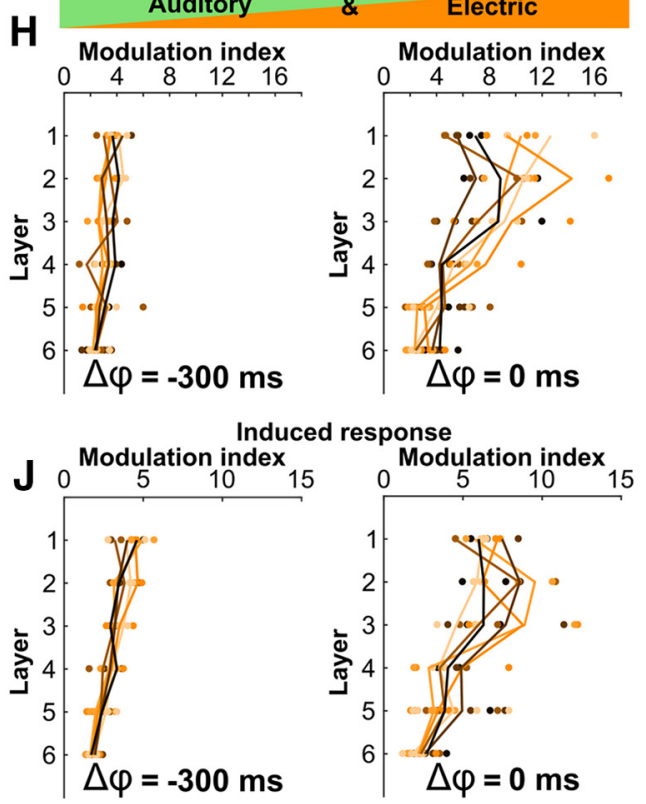

$\Delta \varphi=0 \mathrm{~ms}$
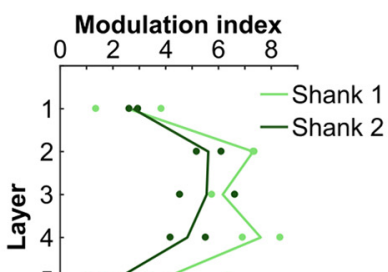

Figure 7. Influence of trial-to-trial prestimulus phase on response amplitudes. $A$, Example LFP in response to acoustic only stimulation, colored according to the instantaneous phase of the signal ( 8 bins, $-\pi$ to $\pi$ ). The dashed green line marks the time of acoustic stimulation and the dotted orange lines mark the possible time points at which in combined stimulation an electrical stimulus was presented. The delays $(\Delta t)$ of 5,15 , and 25 ms ensured that the electric pulse was applied in three different phase bins. $\Delta \varphi$ denotes the time relative to stimulus onset. $B$, Evoked LFP response amplitude (z-scored) for single trials, acoustic only stimulation, as a function of LFP phase at $\Delta \varphi=-300 \mathrm{~ms}$ (left) and $\Delta \varphi=0 \mathrm{~ms}$ (right) for an example electrode. Data of all experiments ( $n=$ 9) and all trials $(n=30)$ were pooled. Each dot marks one trial. The modulation index (MI) was calculated as the maximal minus the minimal bin average ( 8 bins, $-\pi$ to $\pi$, mean \pm SD). C, Same as $\boldsymbol{B}$ for electric only stimulation, at $\Delta \varphi=-300 \mathrm{~ms}$ (left) and $\Delta \varphi=-5 \mathrm{~ms}$ (right). $\boldsymbol{D}$, Ml calculated for instantaneous phase at different prestimulus time points $(\Delta \varphi)$ in acoustic only stimulation. $\boldsymbol{E}$, Same as $\boldsymbol{D}$ for electric only stimulation. Different shades of orange mark different stimulated layers. Mean $\pm S E M$. $\boldsymbol{F}$, Modulation index for auditory only stimulation calculated with phase at $\Delta \varphi=-300 \mathrm{~ms}$ (left) and $\Delta \varphi=0 \mathrm{~ms}$ (right), as a function of recorded layer. Light green, Shank 1; dark green, Shank 2. Each dot represents a single electrode. $\boldsymbol{G}$, Same as $\boldsymbol{F}$ for electric only stimulation. Different shades of orange mark different stimulated layers. $\boldsymbol{H}$, Same as $\mathbf{G}$ for combined stimulation (evoked response, $\Delta t=5 \mathrm{~ms}$ ) calculated for the single-trial amplitude of low-gamma $(30-60 \mathrm{~Hz}$ ) activity. $\boldsymbol{I}$, Same as $\boldsymbol{D}$ for combined stimulation (induced response, $\Delta t=5 \mathrm{~ms}$ ). Different shades of orange mark different stimulated layers. Mean $\pm \mathrm{SEM} \boldsymbol{J}$, Same as $\boldsymbol{H}$ but for the low-gamma activity amplitude in the induced response time-window.

only stimulated with 30 repetitions each, these effects are assumed to play only a minor role, if any, in the observed acute effects (similar to firing rate effects; Voigt et al., 2017).

To resolve whether the response to low-current ICMS integrates into the concurrent processing of a peripheral stimulus or substitutes ongoing processes, we investigated the dependence of the trial-to-trial amplitude on the instantaneous prestimulus network state. A common measure for the network state is the phase of spontaneous oscillations. The phase of spontaneous oscilla- tions is predictive of the response amplitude to a peripheral stimulus on a single trial level (Lakatos et al., 2007, 2008; Kayser et al., 2015). Here we show that this is also true for low-current ICMS. Two conclusions can be drawn: (1) The findings explain why the electrical stimulation resulted in highest evoked amplitudes when stimulating with a stimulus delay of $15 \mathrm{~ms}$ (Fig. 5D), because this corresponds to the electrical stimulus arriving at the optimal phase of network excitability. In the same way Lakatos et al. (2007) used an acoustic stimulus to predetermine the network 
excitability for a second (peripheral, somatosensory) stimulus of a different modality, and also showed supra-additive responses to the combined stimulation as a result. (2) By showing the same dependence of the prestimulus network state as responses to acoustic stimulation, we can exclude that the activity conveyed by low-current electrical stimulation ignored the cortical processing and substituted all ongoing columnar activity. Therefore, the cortical processing of the peripheral click stimulus was not "overwritten" with the activity generated by the electrical stimulus. Instead, the electrical stimulus modulated the ongoing activity.

We propose cortical modulation by means of focused, lowintensity stimulation as an alternative for central neuroprosthetics. Instead of activating large regions without taking into account concurrent network activity, low-current ICMS could modulate the ongoing activity in a closed-loop setting to restore "normal" cortical processing. This would allow to extend the function of a central prosthesis from the traditional "replace" approach, where naturally occurring cortical activity is replaced with activity generated by electrical stimulation (e.g., a traditional sensory implant, recovering a sensory modality by electrical stimulation), to an auxiliary, modulating role. Such prostheses would aim at more decent changes in the neural processing to support the cortex regain its physiological function by reshaping cortical processes. This would extend the indication of central neuroprosthetics from cortical areas that lost peripheral input to cortical areas showing atypical processing.

Such modulatory neuroprostheses could improve cortical network synchronization, either at a columnar level or between cortical areas. For example, previous studies have shown deficits in cortical processing in primary (Kral et al., 2000; Fallon et al., 2009; Beitel et al., 2011) and secondary auditory cortices (Berger et al., 2017; Yusuf et al., 2017) following congenital deafness (Kral and Eggermont, 2007; Kral and Sharma, 2012). Specifically, higher-order functions mediated by the integration of bottom-up and top-down activity were impaired (Kral et al., 2016, 2017), likely leading to suboptimal results of clinically available implantable auditory neuroprostheses (cochlear, auditory brainstem, or auditory midbrain implants). A modulatory neuroprosthesis could be envisioned to modulate the cortical processing of the percepts elicited by these primary auditory prostheses to help restore the correct integration of the bottom-up and top-down information streams.

Another possibility to use modulatory cortical stimulation might be severe treatment-resistant neurological disorders. A range of disorders involve a selective suppression of gamma band oscillatory activity, as observed for example during episodes of negative symptoms of schizophrenia, in certain forms of Alzheimer's disease, or autism spectrum disorders (for reviews, see: Herrmann and Demiralp, 2005; Uhlhaas and Singer, 2006). The observed enhancement of long-latency gamma activity in response to focused stimulation might prove beneficial in patients with these conditions, which are associated with decreased oscillatory activity in this frequency band.

In conclusion, we have found that focused, low-current intracortical microstimulation pulses presented during the cortical processing of peripheral acoustic stimuli enhanced long-latency, induced response components. This represents a modulation of cortical processing, mimicking physiological gain increasing feedback mechanisms. Instead of substituting the natural cortical processes by artificial, electrically conveyed activity, low-current intracortical microstimulation integrated into the existing ongoing activity. This modulation may provide the possibility for physiologically shaping the columnar processing in a targeted way.

\section{References}

Aflalo T, Kellis S, Klaes C, Lee B, Shi Y, Pejsa K, Shanfield K, Hayes-Jackson S, Aisen M, Heck C, Liu C, Andersen RA (2015) Decoding motor imagery from the posterior parietal cortex of a tetraplegic human. Science 348: 906-910. CrossRef Medline

Arieli A, Sterkin A, Grinvald A, Aertsen A (1996) Dynamics of ongoing activity: explanation of the large variability in evoked cortical responses. Science 273:1868-1871. CrossRef Medline

Baranauskas G (2014) What limits the performance of current invasive brain machine interfaces? Front Syst Neurosci 8:68. CrossRef Medline

Beitel RE, Vollmer M, Raggio MW, Schreiner CE (2011) Behavioral training enhances cortical temporal processing in neonatally deafened juvenile cats. J Neurophysiol 106:944-959. CrossRef Medline

Benjamini Y, Hochberg Y (1995) Controlling the false discovery rate: a practical and powerful approach to multiple testing. J R Statist Soc B 57:289-300.

Berger C, Kühne D, Scheper V, Kral A (2017) Congenital deafness affects deep layers in primary and secondary auditory cortex. J Comp Neurol 525:3110-3125. CrossRef Medline

Brosch M, Budinger E, Scheich H (2002) Stimulus-related gamma oscillations in primate auditory cortex. J Neurophysiol 87:2715-2725. CrossRef Medline

Buffalo EA, Fries P, Landman R, Buschman TJ, Desimone R (2011) Laminar differences in gamma and alpha coherence in the ventral stream. Proc Natl Acad Sci U S A 108:11262-11267. CrossRef Medline

Buonomano DV, Maass W (2009) State-dependent computations: spatiotemporal processing in cortical networks. Nat Rev Neurosci 10:113-125. CrossRef Medline

Carrasco A, Lomber SG (2009) Differential modulatory influences between primary auditory cortex and the anterior auditory field. J Neurosci 29: 8350-8362. CrossRef Medline

Castro-Alamancos MA, Connors BW (1996) Short-term plasticity of a thalamocortical pathway dynamically modulated by behavioral state. Science 272:274-277. CrossRef Medline

Chen CC, Kiebel SJ, Kilner JM, Ward NS, Stephan KE, Wang WJ, Friston KJ (2012) A dynamic causal model for evoked and induced responses. Neuroimage 59:340-348. CrossRef Medline

Cicmil N, Krug K (2015) Playing the electric light orchestra: how electrical stimulation of visual cortex elucidates the neural basis of perception. Philos Trans R Soc Lond B Biol Sci 370:20140206. CrossRef Medline

Clark KL, Armstrong KM, Moore T (2011) Probing neural circuitry and function with electrical microstimulation. Proc Biol Sci 278:1121-1130. CrossRef Medline

Cohen MX (2014) Analyzing neural time series data: theory and practice. Cambridge, MA: MIT.

Creutzfeldt OD, Watanabe S, Lux HD (1966) Relations between EEG phenomena and potentials of single cortical cells: I. evoked responses after thalamic and epicortical stimulation. Electroencephalogr Clin Neurophysiol 20:1-18. CrossRef Medline

De Feo V, Boi F, Safaai H, Onken A, Panzeri S, Vato A (2017) Statedependent decoding algorithms improve the performance of a bidirectional bmi in anesthetized rats. Front Neurosci 11:269. CrossRef Medline

Delano PH, Pavez E, Robles L, Maldonado PE (2008) Stimulus-dependent oscillations and evoked potentials in chinchilla auditory cortex. J Comp Physiol A Neuroethol Sens Neural Behav Physiol 194:693-700. CrossRef Medline

De Ribaupierre F, Goldstein MH Jr, Yeni-Komshian G (1972) Intracellular study of the cat's primary auditory cortex. Brain Res 48:185-204. CrossRef Medline

Dimitrijevic A, Smith ML, Kadis DS, Moore DR (2017) Cortical alpha oscillations predict speech intelligibility. Front Hum Neurosci 11:88. CrossRef Medline

Engel AK, Fries P, Singer W (2001) Dynamic predictions: oscillations and synchrony in top-down processing. Nat Rev Neurosci 2:704-716. CrossRef Medline

Fallon JB, Irvine DR, Shepherd RK (2009) Cochlear implant use following neonatal deafness influences the cochleotopic organization of the primary auditory cortex in cats. J Comp Neurol 512:101-114. CrossRef Medline

Flesher SN, Collinger JL, Foldes ST, Weiss JM, Downey JE, Tyler-Kabara EC, 
Bensmaia SJ, Schwartz AB, Boninger ML, Gaunt RA (2016) Intracortical microstimulation of human somatosensory cortex. Sci Transl Med 8:361ra141-361ra141. CrossRef Medline

Fritz JB, Elhilali M, David SV, Shamma SA (2007) Auditory attention: focusing the searchlight on sound. Curr Opin Neurobiol 17:437-455. CrossRef Medline

Ghazanfar AA, Maier JX, Hoffman KL, Logothetis NK (2005) Multisensory integration of dynamic faces and voices in rhesus monkey auditory cortex. J Neurosci 25:5004-5012. CrossRef Medline

Henry MJ, Obleser J (2012) Frequency modulation entrains slow neural oscillations and optimizes human listening behavior. Proc Natl Acad Sci U S A 109:20095-20100. CrossRef Medline

Herrmann CS, Demiralp T (2005) Human EEG gamma oscillations in neuropsychiatric disorders. Clin Neurophysiol 116:2719-2733. CrossRef Medline

Histed MH, Ni AM, Maunsell JH (2013) Insights into cortical mechanisms of behavior from microstimulation experiments. Prog Neurobiol 103: 115-130. CrossRef Medline

Huetz C, Philibert B, Edeline JM (2009) A spike-timing code for discriminating conspecific vocalizations in the thalamocortical system of anesthetized and awake guinea pigs. J Neurosci 29:334-350. CrossRef Medline

Hupé JM, James AC, Payne BR, Lomber SG, Girard P, Bullier J (1998) Cortical feedback improves discrimination between figure and background by V1, V2 and V3 neurons. Nature 394:784-787. CrossRef Medline

Jackson A, Mavoori J, Fetz EE (2006) Long-term motor cortex plasticity induced by an electronic neural implant. Nature 444:56-60. CrossRef Medline

Jaramillo S, Zador AM (2011) The auditory cortex mediates the perceptual effects of acoustic temporal expectation. Nat Neurosci 14:246-251. CrossRef Medline

Kayser C, Wilson C, Safaai H, Sakata S, Panzeri S (2015) Rhythmic auditory cortex activity at multiple timescales shapes stimulus-response gain and background firing. J Neurosci 35:7750-7762. CrossRef Medline

Klink PC, Dagnino B, Gariel-Mathis MA, Roelfsema PR (2017) Distinct feedforward and feedback effects of microstimulation in visual cortex reveal neural mechanisms of texture segregation. Neuron 95:209-220.e3. CrossRef Medline

Konerding WS, Froriep UP, Kral A, Baumhoff P (2018) New thin-film surface electrode array enables brain mapping with high spatial acuity in rodents. Sci Rep 8:3825. CrossRef Medline

Kral A, Eggermont JJ (2007) What's to lose and what's to learn: development under auditory deprivation, cochlear implants and limits of cortical plasticity. Brain Res Rev 56:259-269. CrossRef Medline

Kral A, Sharma A (2012) Developmental neuroplasticity after cochlear implantation. Trends Neurosci 35:111-122. CrossRef Medline

Kral A, Hartmann R, Tillein J, Heid S, Klinke R (2000) Congenital auditory deprivation reduces synaptic activity within the auditory cortex in a layerspecific manner. Cereb Cortex 10:714-726. CrossRef Medline

Kral A, Kronenberger WG, Pisoni DB, O’Donoghue GM (2016) Neurocognitive factors in sensory restoration of early deafness: a connectome model. Lancet Neurol 15:610-621. CrossRef Medline

Kral A, Yusuf PA, Land R (2017) Higher-order auditory areas in congenital deafness: top-down interactions and corticocortical decoupling. Hear Res 343:50-63. CrossRef Medline

Lakatos P, Chen CM, O'Connell MN, Mills A, Schroeder CE (2007) Neuronal oscillations and multisensory interaction in primary auditory cortex. Neuron 53:279-292. CrossRef Medline

Lakatos P, Karmos G, Mehta AD, Ulbert I, Schroeder CE (2008) Entrainment of neuronal oscillations as a mechanism of attentional selection. Science 320:110-113. CrossRef Medline

Lakatos P, Musacchia G, O'Connel MN, Falchier AY, Javitt DC, Schroeder CE (2013) The spectrotemporal filter mechanism of auditory selective attention. Neuron 77:750-761. CrossRef Medline

Lebedev MA (2016) Augmentation of sensorimotor functions with neural prostheses. Opera Med Physiol 2:211-227. CrossRef

Lebedev MA, Nicolelis MA (2017) Brain-machine interfaces: from basic science to neuroprostheses and neurorehabilitation. Physiol Rev 97:767837. CrossRef Medline

Lebedev MA, Ossadtchi A (2018) Commentary: injecting instructions into premotor cortex. Front Cell Neurosci 12:65. CrossRef Medline

Maldonado PE, Gerstein GL (1996) Reorganization in the auditory cortex of the rat induced by intracortical microstimulation: a multiple singleunit study. Exp Brain Res 112:420-430. Medline
Metherate R, Cruikshank SJ (1999) Thalamocortical inputs trigger a propagating envelope of gamma-band activity in auditory cortex in vitro. Exp Brain Res 126:160-174. CrossRef Medline

Morillon B, Hackett TA, Kajikawa Y, Schroeder CE (2015) Predictive motor control of sensory dynamics in auditory active sensing. Curr Opin Neurobiol 31:230-238. CrossRef Medline

Oostenveld R, Fries P, Maris E, Schoffelen JM (2011) FieldTrip: open source software for advanced analysis of MEG, EEG, and invasive electrophysiological data. Comput Intell Neurosci 2011:156869. CrossRef Medline

Pandarinath C, Nuyujukian P, Blabe CH, Sorice BL, Saab J, Willett FR, Hochberg LR, Shenoy KV, Henderson JM (2017) High performance communication by people with paralysis using an intracortical brain-computer interface. eLife 6:e18554. CrossRef Medline

Panzeri S, Safaai H, De Feo V, Vato A (2016) Implications of the dependence of neuronal activity on neural network states for the design of brainmachine interfaces. Front Neurosci 10:165. CrossRef Medline

Poort J, Raudies F, Wannig A, Lamme VA, Neumann H, Roelfsema PR (2012) The role of attention in figure-ground segregation in areas V1 and V4 of the visual cortex. Neuron 75:143-156. CrossRef Medline

Quiroga RQ, Nadasdy Z, Ben-Shaul Y (2004) Unsupervised spike detection and sorting with wavelets and superparamagnetic clustering. Neural Comput 16:1661-1687. CrossRef Medline

Rebesco JM, Stevenson IH, Körding KP, Solla SA, Miller LE (2010) Rewiring neural interactions by micro-stimulation. Front Syst Neurosci 4:39. CrossRef Medline

Rohenkohl G, Cravo AM, Wyart V, Nobre AC (2012) Temporal expectation improves the quality of sensory information. J Neurosci 32:8424-8428. CrossRef Medline

Schwartz AB (2004) Cortical neural prosthetics. Annu Rev Neurosci 27: 487-507. CrossRef Medline

Seeman SC, Mogen BJ, Fetz EE, Perlmutter SI (2017) Paired stimulation for spike-timing-dependent plasticity in primate sensorimotor cortex. J Neurosci 37:1935-1949. CrossRef Medline

Steinschneider M, Fishman YI, Arezzo JC (2008) Spectrotemporal analysis of evoked and induced electroencephalographic responses in primary auditory cortex (A1) of the awake monkey. Cereb Cortex 18:610-625. CrossRef Medline

Sukov W, Barth DS (2001) Cellular mechanisms of thalamically evoked gamma oscillations in auditory cortex. J Neurophysiol 85:1235-1245. CrossRef Medline

Syka J, Šuta D, Popelár J (2005) Responses to species-specific vocalizations in the auditory cortex of awake and anesthetized guinea pigs. Hear Res 206:177-184. CrossRef Medline

Tehovnik EJ (1996) Electrical stimulation of neural tissue to evoke behavioral responses. J Neurosci Methods 65:1-17. CrossRef Medline

Tehovnik EJ, Chen LL (2015) Brain control and information transfer. Exp Brain Res 233:3335-3347. CrossRef Medline

Trautner P, Rosburg T, Dietl T, Fell J, Korzyukov OA, Kurthen M, Schaller C, Elger CE, Boutros NN (2006) Sensory gating of auditory evoked and induced gamma band activity in intracranial recordings. Neuroimage 32:790-798. CrossRef Medline

Uhlhaas PJ, Singer W (2006) Neural synchrony in brain disorders: relevance for cognitive dysfunctions and pathophysiology. Neuron 52:155-168. CrossRef Medline

Voigt MB, Hubka P, Kral A (2017) Intracortical microstimulation differentially activates cortical layers based on stimulation depth. Brain Stimul 10:684-694. CrossRef Medline

Wallace MN, Palmer AR (2008) Laminar differences in the response properties of cells in the primary auditory cortex. Exp Brain Res 184:179-191. CrossRef Medline

Xing D, Yeh CI, Burns S, Shapley RM (2012a) Laminar analysis of visually evoked activity in the primary visual cortex. Proc Natl Acad Sci U S A 109:13871-13876. CrossRef Medline

Xing D, Shen Y, Burns S, Yeh CI, Shapley R, Li W (2012b) Stochastic generation of gamma-band activity in primary visual cortex of awake and anesthetized monkeys. J Neurosci 32:13873-13880a. CrossRef Medline

Yusuf PA, Hubka P, Tillein J, Kral A (2017) Induced cortical responses require developmental sensory experience. Brain 140:3153-3165. CrossRef Medline

Zrenner C, Desideri D, Belardinelli P, Ziemann U (2018) Real-time EEGdefined excitability states determine efficacy of TMS-induced plasticity in human motor cortex. Brain Stimul 11:374-389. CrossRef Medline 